\title{
Multiply-deuterated species in prestellar cores ${ }^{\star}$
}

\author{
D. R. Flower ${ }^{1}$, G. Pineau des Forêts ${ }^{2,3}$, and C. M. Walmsley ${ }^{4}$
}

\author{
1 Physics Department, The University, Durham DH1 3LE, UK \\ 2 IAS, Université de Paris-Sud, 92405 Orsay Cedex, France \\ 3 LUTH, Observatoire de Paris, 92195 Meudon Cedex, France \\ ${ }^{4}$ INAF, Osservatorio Astrofisico di Arcetri, Largo Enrico Fermi 5, 50125 Firenze, Italy
}

Received 14 June 2004 / Accepted 5 August 2004

\begin{abstract}
We have studied the ortho, para, and, in the case of $\mathrm{D}_{3}^{+}$, meta forms of the multiply-deuterated isotopes of $\mathrm{H}_{3}^{+}$, under physical conditions believed to be appropriate to pre-protostellar cores. As deuterons have integral nuclear spin, $I=1$, Bose-Einstein statistical laws apply. Having extended the network of chemical reactions used in our previous study (Walmsley et al. 2004), we have calculated the population densities of ortho- and para- $\mathrm{D}_{2} \mathrm{H}^{+}$and of ortho- and meta- $\mathrm{D}_{3}^{+}$. In the former case, comparison is made with the recent observations of para- $\mathrm{D}_{2} \mathrm{H}^{+}$in the prestellar core 16293E (Vastel et al. 2004). Using radiative transition probabilities computed by Ramanlal \& Tennyson (2004), we have predicted the intensities of the near infrared vibrational transitions of the deuterated isotopes of $\mathrm{H}_{3}^{+}$. Many of these transitions can be observed, in absorption, only from above the Earth's atmosphere, but some might be detectable through atmospheric windows.
\end{abstract}

Key words. stars: formation - astrochemistry - ISM: clouds

\section{Introduction}

Recent observations of $\mathrm{H}_{2} \mathrm{D}^{+}$(Caselli et al. 2003; Ceccarelli et al. 2004) and additionally of $\mathrm{D}_{2} \mathrm{H}^{+}$(Vastel et al. 2004) have provided striking evidence of the extent of deuteration of $\mathrm{H}_{3}^{+}$in the cold, dense gas of the interstellar medium. The removal of "heavy" molecules, i.e. molecules containing elements heavier than helium, is believed to occur at high densities $\left(n_{\mathrm{H}} \gtrsim\right.$ $10^{5} \mathrm{~cm}^{-3}$ ) and low temperatures $(T \lesssim 10 \mathrm{~K}$ ) by adsorption on to grains. It is accompanied by deuteration reactions with HD along the exothermic sequence $\mathrm{H}_{3}^{+} \rightarrow \mathrm{H}_{2} \mathrm{D}^{+} \rightarrow \mathrm{D}_{2} \mathrm{H}^{+} \rightarrow \mathrm{D}_{3}^{+}$ (Roberts et al. 2003; Walmsley et al. 2004). Observations of the deuterated forms of $\mathrm{H}_{3}^{+}$, in conjunction with models of the deuteration process, enable information to be obtained on the conditions in media where stars are beginning to form, through gravitational contraction.

All four of the molecular ions $\mathrm{H}_{3}^{+}, \mathrm{H}_{2} \mathrm{D}^{+}, \mathrm{D}_{2} \mathrm{H}^{+}$and $\mathrm{D}_{3}^{+}$ have "ortho" and "para" (and, in the case of $\mathrm{D}_{3}^{+}$, "meta") forms, corresponding to the spin states of the protons (in $\mathrm{H}_{3}^{+}$ and $\mathrm{H}_{2} \mathrm{D}^{+}$) or the deuterons (in $\mathrm{D}_{2} \mathrm{H}^{+}$and $\mathrm{D}_{3}^{+}$). Models of the deuteration process should distinguish between these forms, not only because the observations relate to specific modifications (ortho- $\mathrm{H}_{2} \mathrm{D}^{+}$and para- $\mathrm{D}_{2} \mathrm{H}^{+}$) but also because the exo/endothermicities of the forwards and reverse reactions involved in deuteration depend on the forms of the reactants and products. The ortho:para ratios of the species $\mathrm{H}_{3}^{+}$and $\mathrm{H}_{2} \mathrm{D}^{+}$are linked to the ratio of ortho- to para- $\mathrm{H}_{2}$ (which are produced in

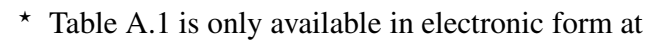
http://www.edpsciences.org grain-surface reactions), through the proton-exchanging reaction of $\mathrm{H}_{3}^{+}$with $\mathrm{H}_{2}$ and the formation of $\mathrm{H}_{2} \mathrm{D}^{+}$in the reaction $\mathrm{H}_{3}^{+}\left(\mathrm{HD}, \mathrm{H}_{2}\right) \mathrm{H}_{2} \mathrm{D}^{+}$. On the other hand, the abundances of the ortho and para forms of $\mathrm{D}_{2} \mathrm{H}^{+}$, and the ortho, para and meta forms of $\mathrm{D}_{3}^{+}$are determined by reactions (principally with HD, which is also produced on grains) which modify the overall spin symmetry of the deuterons. Deuterons, unlike protons, have spin $I=1$ and hence obey Bose-Einstein statistical laws.

In the present paper, we build on and extend our previous study of complete depletion in pre-protostellar cores by considering explicitly the ortho and para forms of $\mathrm{D}_{2} \mathrm{H}^{+}$and other species containing two deuterons, and the ortho and meta forms of $\mathrm{D}_{3}^{+}$. We determine their dependence on the physical conditions in the medium, including the properties of the grains. As defined in Sect. 2 of our previous paper, "complete depletion" implies gas-phase fractional abundances of species such as $\mathrm{CO}$ much less than $10^{-6}$.

\section{Chemical model}

The multiply-deuterated species $\mathrm{D}_{2}, \mathrm{D}_{2}^{+}, \mathrm{D}_{2} \mathrm{H}^{+}$and $\mathrm{D}_{3}^{+}$have been incorporated already in our previous model (Walmsley et al. 2004). However, we assumed that the chemical reactions implicated only their lowest energy states, of ortho symmetry. We now extend our study by considering the other modifications of these multiply-deuterated species. We discuss first those species containing two deuterons, and then $\mathrm{D}_{3}^{+}$separately. 
Table 1. Statistical properties of the ortho and para forms of $D_{2}$ (Herzberg 1950). The ortho nuclear spin states are associated with even values of the rotational quantum number, $J$, and the para states with odd $J$. Only the lowest rotational level of each modification was included in the model. For $\mathrm{D}_{2}^{+}$and $\mathrm{D}_{2} \mathrm{H}^{+}$, the statistical properties of the lowest ortho and para levels are the same as in the case of $\mathrm{D}_{2}$; but the lowest para level lies $42.0 \mathrm{~K}$ and $50.2 \mathrm{~K}$, respectively, above the lowest ortho level, which is the ground level (Polyansky \& Tennyson 1999; Ramanlal \& Tennyson 2004).

\begin{tabular}{crccccr}
\hline \hline Modification & $I_{\text {tot }}$ & $\sum\left(2 I_{\text {tot }}+1\right)$ & $J$ & $(2 J+1)$ & $(2 J+1) \sum\left(2 I_{\text {tot }}+1\right)$ & $E_{J}(\mathrm{~K})$ \\
\hline ortho & 0,2 & 6 & 0 & 1 & 6 & 0 \\
para & 1 & 3 & 1 & 3 & 9 & 86.0 \\
\hline
\end{tabular}

Table 2. Statistical properties of the energy levels of $\mathrm{D}_{3}^{+}$with $J=0$ and $J=1 . J$ is the rotational quantum number and $K$ its projection on the molecular symmetry axis; $g_{I}$ is the nuclear spin statistical weight. Only the two lowest energy levels, of A1 and E symmetry, were included in the model. The energies were computed by Polyansky \& Tennyson (1999). Note that $1 \mathrm{~cm}^{-1} \equiv 1.4388 \mathrm{~K}$.

\begin{tabular}{rrrccrrr}
\hline \hline$J$ & $K$ & Energy $\left(\mathrm{cm}^{-1}\right)$ & Symmetry & Modification & $g_{I}$ & $(2 J+1) g\left(I_{\text {tot }}\right)$ & $E_{J K}(\mathrm{~K})$ \\
\hline 0 & 0 & 0.000 & A1 & ortho & 10 & 10 & 0.0 \\
1 & 1 & 32.331 & E & meta & 8 & 24 & 46.5 \\
1 & 0 & 43.619 & A2 & para & 1 & 3 & 62.8 \\
\hline
\end{tabular}

\subsection{Species containing two deuterons}

The template in this case is $\mathrm{D}_{2}$, whose spectroscopic properties were discussed by Herzberg (1950). A deuteron has a spin quantum number $I=1$ and a spin statistical weight $2 I+1=3$. The total spin statistical weight of $\mathrm{D}_{2}$ is $\prod_{i=1}^{2}\left(2 I_{i}+1\right)=9$, where the deuterons are labelled " 1 " and " 2 ". Of the three possible values of the resultant nuclear spin, $I_{\text {tot }}=0,1,2$, two $\left(I_{\text {tot }}=0,2\right)$ are associated with states which are symmetric under exchange of the (identical) deuterons, whereas $I_{\text {tot }}=1$ is associated with states which are antisymmetric under deuteron exchange. The symmetric states, which are $\sum\left(2 I_{\text {tot }}+1\right)=6$ in number, are denoted "ortho", whereas the 3 antisymmetric states are denoted "para". These facts are summarized in Table 1.

When Bose-Einstein statistical laws apply, as here, the total (nuclear) wave function, which is a product of the spin and the rotational components, must be symmetric under exchange of identical bosons. As the rotational wave function has symmetry $(-1)^{J}$ under exchange of the nucleons, where $J$ is the rotational quantum number, it follows that the lowest rotational level, $J=0$, must have ortho symmetry, and the first excited level, $J=1$, must have para symmetry. Thus, the total statistical weight of the ground rotational level is 6 , whereas that of the first excited rotational level is 9 (cf. Table 1). The first excited level lies at an energy $E_{J=1} / k=86.0 \mathrm{~K}$ above the $J=0$ ground level (Herzberg 1950). We neglect levels $J \geq 2$, taking $J=0$ to represent the ortho levels and $J=1$ to represent the para levels. In the case of $\mathrm{D}_{2}^{+}$, the $J=1$ level lies $42.0 \mathrm{~K}$ above $J=0$ (using the spectroscopic constants of Herzberg (1950) for $\mathrm{H}_{2}^{+}$and allowing for the different reduced mass of $\mathrm{D}_{2}^{+}$). In $\mathrm{D}_{2} \mathrm{H}^{+}$, the lowest para level lies $50.2 \mathrm{~K}$ above the lowest ortho (ground) level (Polyansky \& Tennyson 1999; Ramanlal \& Tennyson 2004).

\section{2. $D_{3}^{+}$}

The triply deuterated form of $\mathrm{H}_{3}^{+}\left(\mathrm{D}_{3}^{+}\right)$, needs separate consideration. Polyansky \& Tennyson (1999) computed the energies of the rovibrational levels of $\mathrm{H}_{3}^{+}$and all its deuterated isotopes, including $\mathrm{D}_{3}^{+}$, to spectroscopic accuracy. Ramanlal \& Tennyson (2004) have recently provided the corresponding radiative transition probabilities.

In Table 2 are shown the lowest energy states of $\mathrm{D}_{3}^{+}$, together with their computed energies. Following the presentation by Townes \& Schawlow (1955; see their Table 3-6), we deduce that: the lowest (ground) level, of A1 symmetry, has a nuclear spin statistical weight, $g_{I}=10$; the first excited state, of E symmetry, has $g_{I}=8$; and the second excited state, of A2 symmetry, has $g_{I}=1$. The statistical weights and associated energies are listed in Table 2. We neglect the second excited state, of A2 symmetry, which has the lowest statistical weight. The ground state, which has the highest statistical weight (10), is denoted "ortho", and the first excited state is denoted "meta"; the second excited state, which we neglect, is denoted "para". Although the use of terms such as "ortho" and "para" is not strictly appropriate in this case, it serves to distinguish the energy levels. Thus, the "ortho" level is again the lowest, with a total statistical weight (the product of the nuclear spin statistical weight, $g_{I}$, with $(2 J+1)$ ) of 10 . The "meta" level has a total statistical weight of 24 .

\section{Results}

Our previous study (Walmsley et al. 2004) was directed towards understanding the observation of ortho- $\mathrm{H}_{2} \mathrm{D}^{+}$in L1544; the "ortho", "para" and "meta" forms of multiply-deuterated species were not distinguished in those calculations. We have since found that the introduction of the distinction between the modifications has only modest effects on the results which we obtained and presented previously. Figure 1 illustrates this close similarity; it should be compared with Fig. 2 of Walmsley et al. (2004) and applies to the "reference" model: a grain radius $a_{\mathrm{g}}=0.1 \mu \mathrm{m}$, a kinetic temperature $T=10 \mathrm{~K}$, and a cosmic ray ionization rate $\zeta=3 \times 10^{-17} \mathrm{~s}^{-1}$. As previously, the fractional abundances which we plot are those in steady state. 


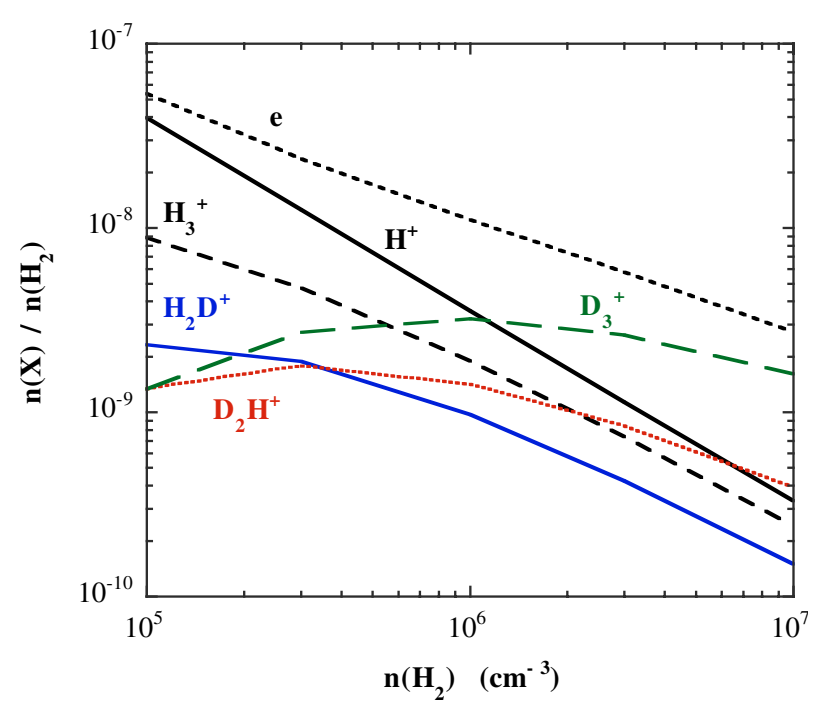

Fig. 1. Steady-state abundances of major ions and electrons in the standard model $\left(a_{\mathrm{g}}=0.1 \mu \mathrm{m}, T=10 \mathrm{~K}, \zeta=3 \times 10^{-17} \mathrm{~s}^{-1}\right)$ as functions of the density of molecular hydrogen.

We now turn our attention to the multiply-deuterated species and, in particular, their modifications. We shall consider variations with respect to the gas density and temperature and the grain radius.

\subsection{Dependence on $n\left(H_{2}\right)$}

In Fig. 2, we plot the ratios para/ortho $\mathrm{D}_{2} \mathrm{H}^{+}$, meta/ortho $\mathrm{D}_{3}^{+}$, and para/ortho $\mathrm{D}_{2}$ as functions of the molecular hydrogen density. It should be recalled that "ortho" refers to the lowest (ground) state and "para" or "meta" to the first excited state of these multiply-deuterated species. Results are given for the reference model $\left(a_{\mathrm{g}}=0.1 \mu \mathrm{m}, T=10 \mathrm{~K}\right.$, and $\left.\zeta=3 \times 10^{-17} \mathrm{~s}^{-1}\right)$.

In all three cases $\left(\mathrm{D}_{2} \mathrm{H}^{+}, \mathrm{D}_{3}^{+}\right.$, and $\left.\mathrm{D}_{2}\right)$, the ratio of the excited to the ground state population density decreases with $n_{\mathrm{H}}$, owing to the enhanced rates of deuteron exchange reactions, which interconnect the modifications. The para/ortho $\mathrm{D}_{2} \mathrm{H}^{+}$ and meta/ortho $\mathrm{D}_{3}^{+}$ratios are determined principally by deuteron-exchanging reactions with $\mathrm{HD}$, whose fractional abundance, $n(\mathrm{HD}) / n\left(\mathrm{H}_{2}\right)$, is almost independent of $n\left(\mathrm{H}_{2}\right)$, as may be seen from Fig. 3. (Most of the deuterium in the medium is present in the form of $\mathrm{HD}$, and of hydrogen in the form of $\mathrm{H}_{2}$, and hence $n(\mathrm{HD}) / n\left(\mathrm{H}_{2}\right) \approx 2 n_{\mathrm{D}} / n_{\mathrm{H}}=3.2 \times 10^{-5}$.)

In local thermodynamic equilibrium (LTE) at $T=10 \mathrm{~K}$, the ratios of the excited to ground state densities are 0.045, 0.010 , and $2.8 \times 10^{-4}$ for $\mathrm{D}_{3}^{+}, \mathrm{D}_{2} \mathrm{H}^{+}$, and $\mathrm{D}_{2}$, respectively. Thus, even at $n\left(\mathrm{H}_{2}\right)=10^{7} \mathrm{~cm}^{-3}$, none of these ratios has reached its LTE value. The para/ortho $\mathrm{D}_{2}$ ratio is determined by dissociative recombination of $\mathrm{D}_{3}^{+}$with electrons in the gas phase and on the surfaces of negatively charged grains and, at high densities, by deuteron-exchanging reactions with $\mathrm{D}_{3}^{+}$, which becomes the major ion (cf. Fig. 1). The fact that reactions involving five deuterons should assume significance is indicative of the very particular conditions which prevail in pre-protostellar cores. These same deuteron-exchanging reactions of $\mathrm{D}_{2}$ with $\mathrm{D}_{3}^{+}$also have some influence on the meta/ortho

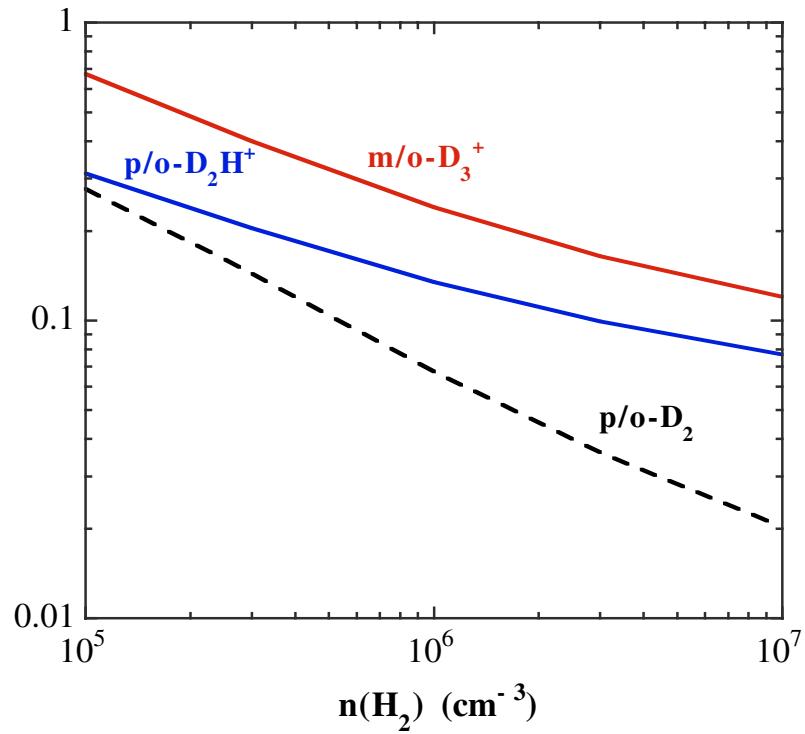

Fig. 2. Steady-state values of the para/ortho $\mathrm{D}_{2}$ and $\mathrm{D}_{2} \mathrm{H}^{+}$ratios and the meta/ortho $\mathrm{D}_{3}^{+}$ratio, as functions of the molecular hydrogen density $\left(a_{\mathrm{g}}=0.1 \mu \mathrm{m}, T=10 \mathrm{~K}, \zeta=3 \times 10^{-17} \mathrm{~s}^{-1}\right)$.

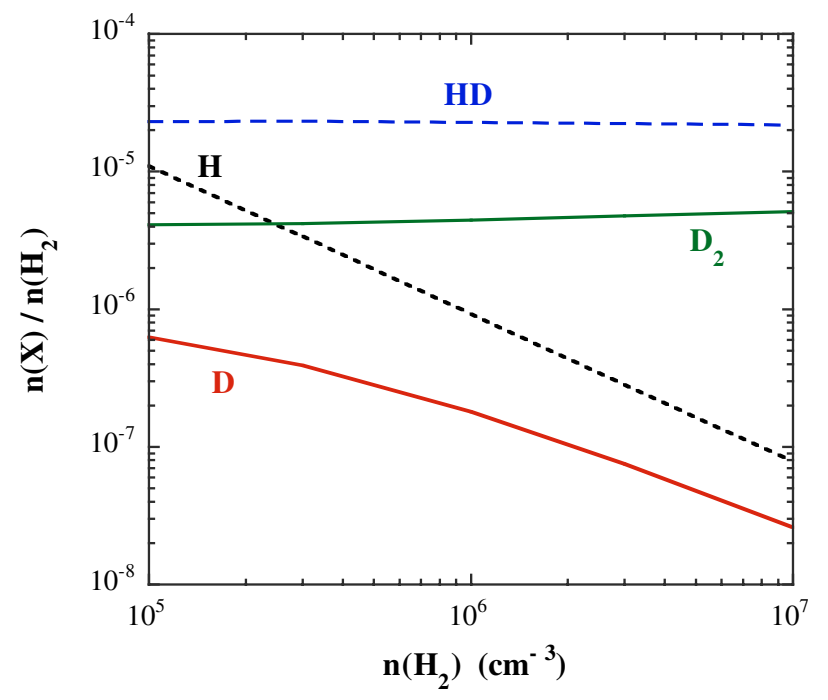

Fig. 3. Steady-state fractional abundances of $\mathrm{HD}$ and $\mathrm{D}_{2}$, as functions of the molecular hydrogen density. The fractional abundances of atomic $\mathrm{H}$ and $\mathrm{D}$ are also plotted $\left(a_{\mathrm{g}}=0.1 \mu \mathrm{m}, T=10 \mathrm{~K}, \zeta=3 \times\right.$ $\left.10^{-17} \mathrm{~s}^{-1}\right)$.

$\mathrm{D}_{3}^{+}$ratio, and the corresponding reactions of $\mathrm{D}_{2}$ with $\mathrm{D}_{2} \mathrm{H}^{+}$ modify the para/ortho $\mathrm{D}_{2} \mathrm{H}^{+}$ratio. However, the fractional abundance of $\mathrm{D}_{2},\left[\mathrm{D}_{2}\right]<[\mathrm{HD}]$, as Fig. 3 shows, and so the meta/ortho $\mathrm{D}_{3}^{+}$and para/ortho $\mathrm{D}_{2} \mathrm{H}^{+}$ratios are determined principally by deuteron-exchanging reactions with $\mathrm{HD}$, as already mentioned. As may be seen from Fig. 3, the fractional abundance of atomic $\mathrm{D}$ approaches that of $\mathrm{H}$ at high density.

\subsection{Dependence on $T$}

As the temperature of the gas increases, the degree of deuteration of $\mathrm{H}_{3}^{+}$is expected to fall, owing to the reverse sequence $\mathrm{D}_{3}^{+} \rightarrow \mathrm{D}_{2} \mathrm{H}^{+} \rightarrow \mathrm{H}_{2} \mathrm{D}^{+} \rightarrow \mathrm{H}_{3}^{+}$; these reactions, with $\mathrm{H}_{2}$, are endothermic (Ramanlal et al. 2003) and their rates increase 


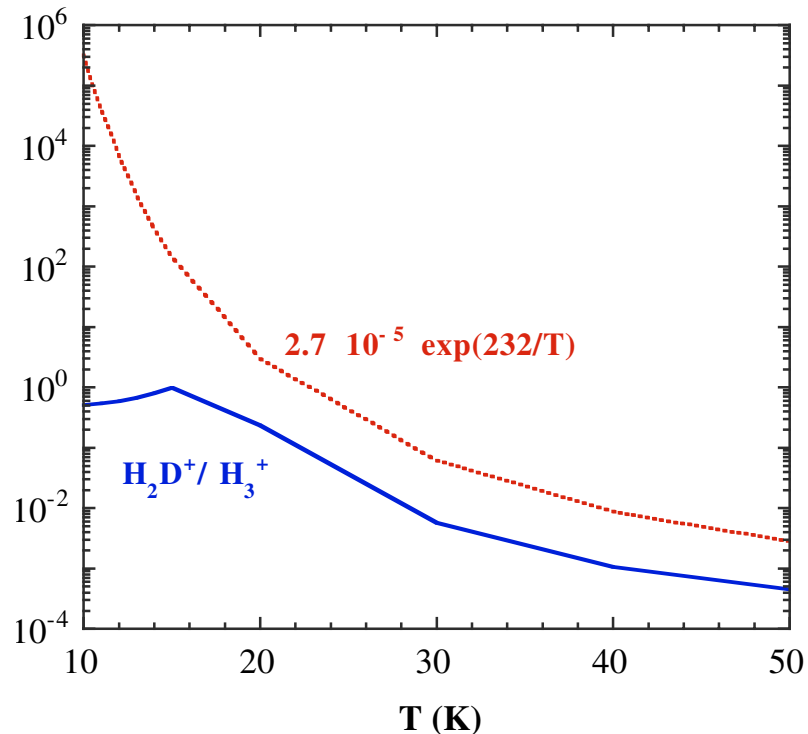

Fig. 4. The ratio $n\left(\mathrm{H}_{2} \mathrm{D}^{+}\right) / n\left(\mathrm{H}_{3}^{+}\right)$, computed for $n_{\mathrm{H}}=2 \times 10^{6} \mathrm{~cm}^{-3}$ and $a_{\mathrm{g}}=0.1 \mu \mathrm{m}$, as a function of the gas kinetic temperature, $T$. The value of the ratio in LTE is also plotted.

rapidly with the kinetic temperature, $T$. Furthermore, the ratios of the excited to ground state population densities of the multiply-deuterated species might be expected to increase as $T$ increases. These points are illustrated in Figs. 4 and 5, where the ratios $n\left(\right.$ para- $\left.\mathrm{H}_{2} \mathrm{D}^{+}\right) / n\left(\right.$ para- $\left.\mathrm{H}_{3}^{+}\right)$and $n\left(\right.$ para- $\left.\mathrm{D}_{2} \mathrm{H}^{+}\right) / n$ (ortho$\left.\mathrm{D}_{2} \mathrm{H}^{+}\right), n\left(\right.$ meta- $\left.\mathrm{D}_{3}^{+}\right) / n\left(\right.$ ortho- $\mathrm{D}_{3}^{+}$) are plotted against $T$. Also plotted in these Figures are the values of the ratios corresponding to LTE.

Under conditions of thermodynamic equilibrium, when the rates per unit volume of forwards and reverse reactions are equal, the reaction para- $\mathrm{H}_{3}^{+}\left(\mathrm{HD}\right.$, para- $\left.\mathrm{H}_{2}\right)$ para- $\mathrm{H}_{2} \mathrm{D}^{+}$, which is exoergic by $232 \mathrm{~K}$ in the forwards direction, would give rise to an abundance ratio

$$
\frac{n\left(\mathrm{H}_{2} \mathrm{D}^{+}\right)}{n\left(\mathrm{H}_{3}^{+}\right)}=\frac{k_{f}}{k_{r}} \exp (232 / T) \frac{n(\mathrm{HD})}{n\left(\mathrm{H}_{2}\right)} \text {. }
$$

Taking $k_{f}=1.17 \times 10^{-10} \mathrm{~cm}^{3} \mathrm{~s}^{-1}, k_{r}=1.40 \times 10^{-10} \mathrm{~cm}^{3} \mathrm{~s}^{-1}$, and $n(\mathrm{HD}) / n\left(\right.$ para- $\left.\mathrm{H}_{2}\right)=3.2 \times 10^{-5}$, we obtain

$$
\frac{n\left(\mathrm{H}_{2} \mathrm{D}^{+}\right)}{n\left(\mathrm{H}_{3}^{+}\right)}=2.7 \times 10^{-5} \exp (232 / T) \text {. }
$$

Figure 4 shows that the calculated abundance ratio tends towards its LTE value as $T$ increases, although only slowly because of the large energy defect involved in the para$\mathrm{H}_{3}^{+}\left(\mathrm{HD}\right.$, para- $\left.\mathrm{H}_{2}\right)$ para- $\mathrm{H}_{2} \mathrm{D}^{+}$reaction. The para/ortho $\mathrm{D}_{2} \mathrm{H}^{+}$ and meta/ortho $\mathrm{D}_{3}^{+}$ratios also approach their LTE values with increasing $T$, as may be seen in Fig. 5. However, the para/ortho $\mathrm{D}_{2} \mathrm{H}^{+}$ratio has still not reached its LTE value at $T=50 \mathrm{~K}$. Furthermore, the meta/ortho $\mathrm{D}_{3}^{+}$ratio does not attain its LTE value, owing to reactions other than those (with HD) which interconvert the ortho and meta forms. Both the para/ortho ratio of $\mathrm{D}_{2} \mathrm{H}^{+}$and the meta/ortho ratio of $\mathrm{D}_{3}^{+}$ are superthermal at low $T$. The exoergicities of the deuteration reactions $\mathrm{H}_{2} \mathrm{D}^{+}\left(\mathrm{HD}, \mathrm{H}_{2}\right) \mathrm{D}_{2} \mathrm{H}^{+}$and $\mathrm{D}_{2} \mathrm{H}^{+}\left(\mathrm{HD}, \mathrm{H}_{2}\right) \mathrm{D}_{3}^{+}$are sufficient to give rise to overpopulation of the excited (para
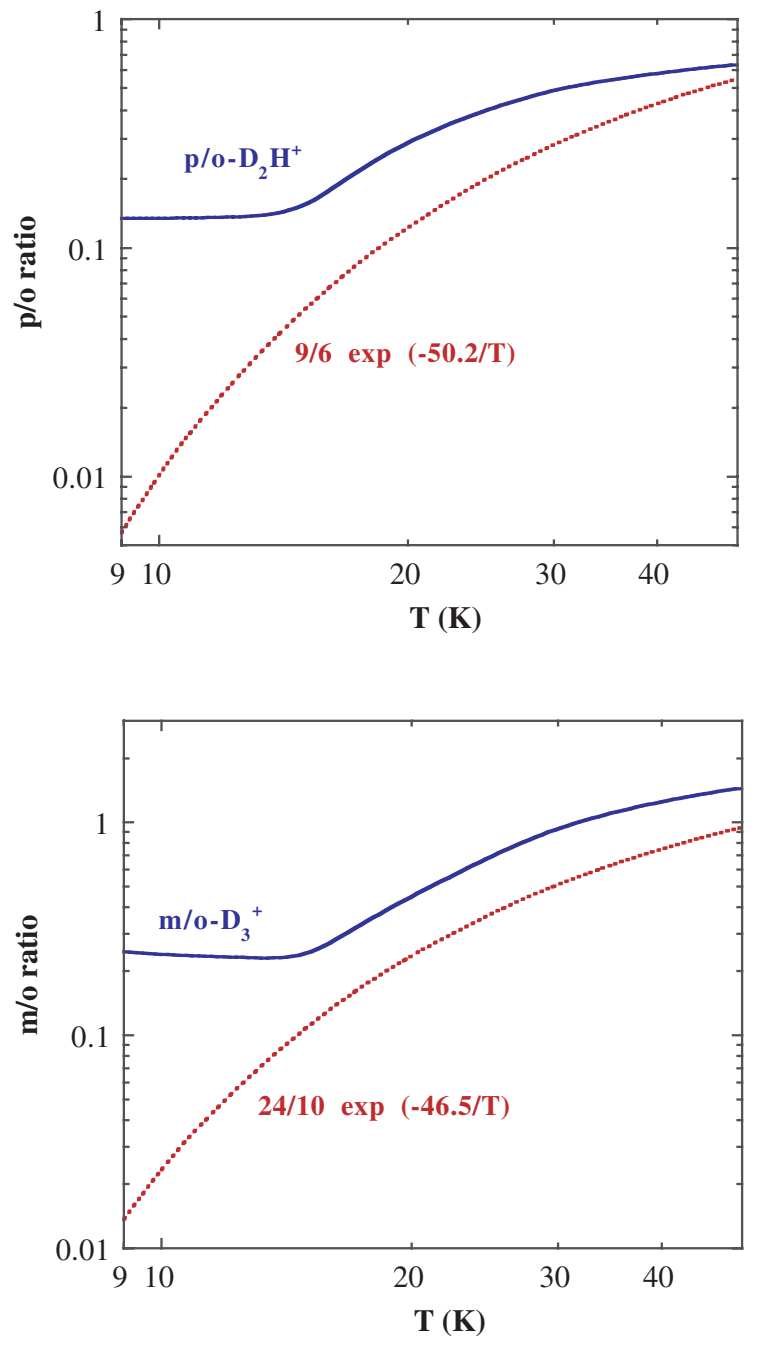

Fig. 5. The the para/ortho $\mathrm{D}_{2} \mathrm{H}^{+}$and meta/ortho $\mathrm{D}_{3}^{+}$ratios, computed for $n\left(\mathrm{H}_{2}\right)=10^{6} \mathrm{~cm}^{-3}$ and $a_{\mathrm{g}}=0.1 \mu \mathrm{m}$, as functions of the gas kinetic temperature, $T$. The values of the ratios in LTE are also plotted.

and meta) levels at low temperatures, where the reactions are strongly favoured in the forwards (deuteration) direction (see Appendix B, where we derive an approximate expression for the meta/ortho $\mathrm{D}_{3}^{+}$ratio at low temperatures).

For completeness, the ortho/para $\mathrm{H}_{3}^{+}$and $\mathrm{H}_{2} \mathrm{D}^{+}$ratios are plotted in Fig. 6; these ratios also are superthermal at low $T$. Note that the ortho/para $\mathrm{H}_{3}^{+}$ratio does not reach its LTE value until $T$ approaches $20 \mathrm{~K}$. Thus, the assumption that the gas kinetic temperature may be derived from the observed value of this ratio, assuming LTE, is not valid at low $T$. In fact, the calculated values of the ratios plotted in Fig. 6 are double-valued: within certain ranges, the observed values of these ratios can correspond to either low-temperature non-LTE or higher temperature LTE solutions.

Vastel et al. (2004) have measured the column densities of ortho- $\mathrm{H}_{2} \mathrm{D}^{+}$and para- $\mathrm{D}_{2} \mathrm{H}^{+}$in the prestellar core $16293 \mathrm{E}$, obtaining a ratio $N\left(\right.$ para- $\left.\mathrm{D}_{2} \mathrm{H}^{+}\right) / N\left(\right.$ ortho- $\left.\mathrm{H}_{2} \mathrm{D}^{+}\right)=0.75$ for an excitation temperature $T_{\mathrm{ex}}=10 \mathrm{~K}$ (and assuming that the source is more extended that the observing beam). The calculated value of the ratio $n\left(\right.$ para- $\left.\mathrm{D}_{2} \mathrm{H}^{+}\right) / n\left(\right.$ ortho- $\left.\mathrm{H}_{2} \mathrm{D}^{+}\right)$, as a function of $T$, is shown in Fig. 7. It may be seen from Fig. 7 that the 

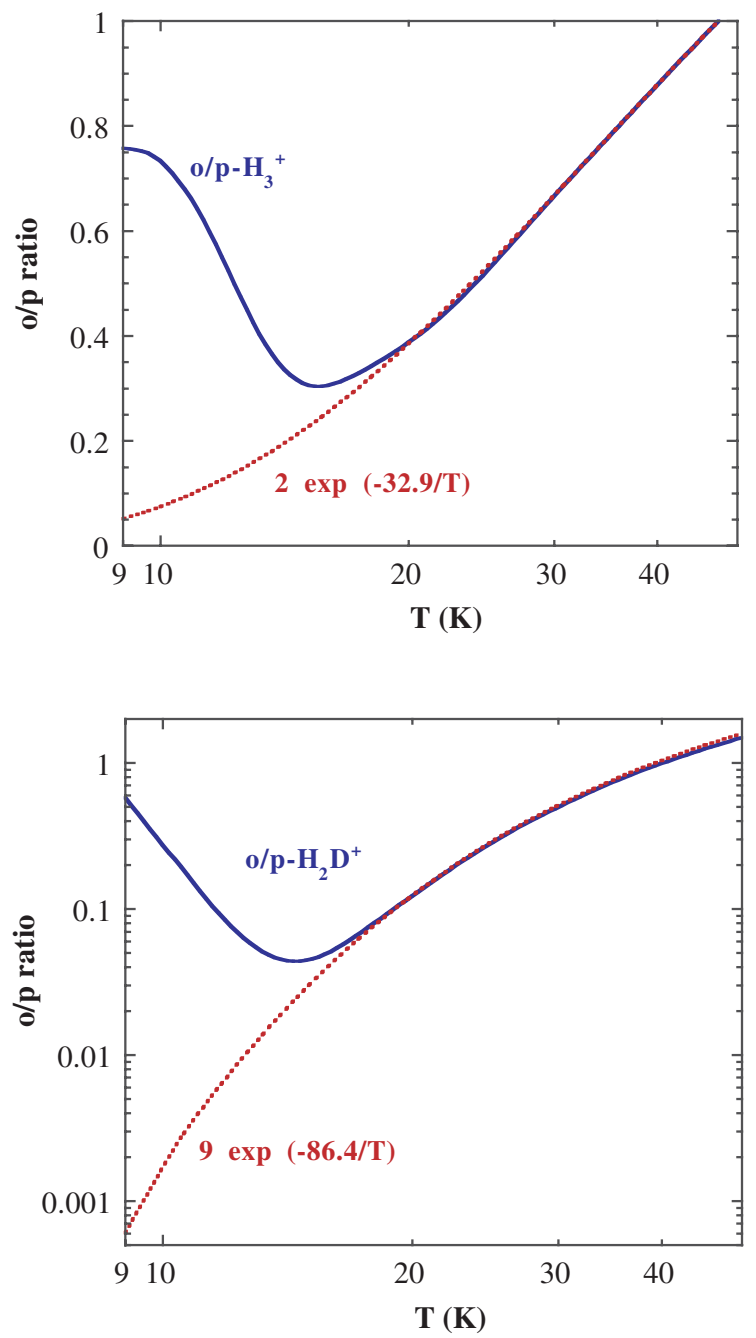

Fig. 6. The the ortho/para $\mathrm{H}_{3}^{+}$and $\mathrm{H}_{2} \mathrm{D}^{+}$ratios, computed for $n_{\mathrm{H}}=2 \times$ $10^{6} \mathrm{~cm}^{-3}$ and $a_{\mathrm{g}}=0.1 \mu \mathrm{m}$, as functions of the gas kinetic temperature, $T$. The values of the ratios in LTE are also plotted.

value calculated at $T=10 \mathrm{~K}$ is consistent with that "observed". However, we have just shown that neither the para/ortho $\mathrm{D}_{2} \mathrm{H}^{+}$ nor the ortho/para $\mathrm{H}_{2} \mathrm{D}^{+}$ratio is in LTE at $T=10 \mathrm{~K}$, and so this apparently good agreement should be viewed with circumspection. Moreover, the work of Mizuno et al. (1990) and Stark et al. (2004) suggests that a temperature in the range $12 \leq T \leq 16 \mathrm{~K}$ may be more appropriate to $16293 \mathrm{E}$.

The ortho/para $\mathrm{H}_{2} \mathrm{D}^{+}$and para/ortho $\mathrm{D}_{2} \mathrm{H}^{+}$ratios are superthermal at low $T$. Thermalization (with increasing $T$ ) leads to an initial decrease in both ratios, with the first decreasing faster than the second owing to the larger ortho:para separation in $\mathrm{H}_{2} \mathrm{D}^{+}\left(86 \mathrm{~K}\right.$, as compared with $50 \mathrm{~K}$ in $\left.\mathrm{D}_{2} \mathrm{H}^{+}\right)$. Thus, the ratio $n\left(\right.$ para- $\left.\mathrm{D}_{2} \mathrm{H}^{+}\right) / n$ (ortho- $\mathrm{H}_{2} \mathrm{D}^{+}$) tends to increase with $T$ at low $T$. As LTE is approached, these trends are reversed, with ortho/para $\mathrm{H}_{2} \mathrm{D}^{+}$increasing faster than para/ortho $\mathrm{D}_{2} \mathrm{H}^{+}$, and hence $n\left(\right.$ para- $\left.\mathrm{D}_{2} \mathrm{H}^{+}\right) / n$ (ortho- $\left.\mathrm{H}_{2} \mathrm{D}^{+}\right)$decreases as $T$ increases further, as may be seen in Fig. 7.

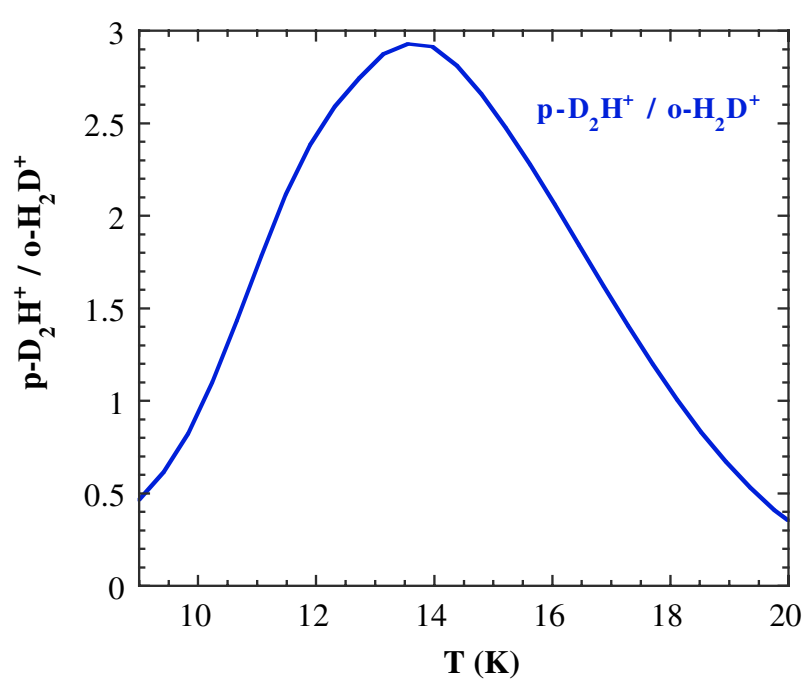

Fig. 7. The ratio $n\left(\right.$ para- $\left.\mathrm{D}_{2} \mathrm{H}^{+}\right) / n$ (ortho- $\left.\mathrm{H}_{2} \mathrm{D}^{+}\right)$, computed for $n_{\mathrm{H}}=2 \times$ $10^{6} \mathrm{~cm}^{-3}$ and $a_{\mathrm{g}}=0.1 \mu \mathrm{m}$, as a function of the gas kinetic temperature, $T$. (Vastel et al. (2004) have reported a value of 0.75 for this ratio in the prestellar core 16293E (see text, Sect. 3.2).)

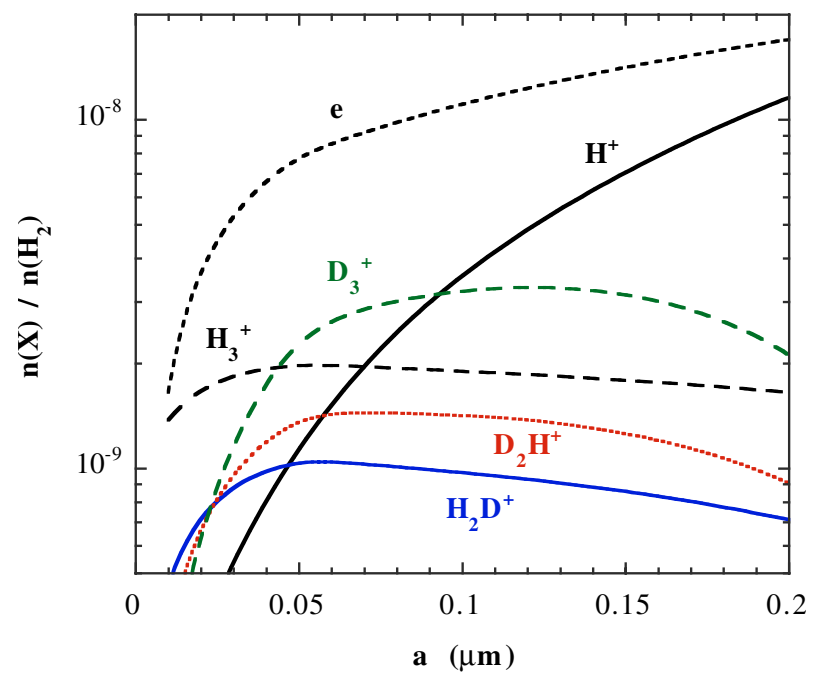

Fig. 8. The fractional abundances of the major ions and the free electron abundance plotted against the grain radius, $a_{\mathrm{g}}$, for a density of $n_{\mathrm{H}}=2 \times 10^{6} \mathrm{~cm}^{-3}, T=10 \mathrm{~K}$, and $\zeta=3 \times 10^{-17} \mathrm{~s}^{-1}$.

\subsection{Dependence on $a_{g}$}

In our calculations, we have assumed all the grains to have the same size, but we have investigated the dependence of the results on the grain radius, $a_{\mathrm{g}}$. We recall that it is the grain surface area per hydrogen nucleus which is relevant to the rates of gas-grain reactions.

As in our previous paper (Walmsley et al. 2004), we present results with reference to a model with the grain parameters $a_{\mathrm{g}}=0.1 \mu \mathrm{m}$ and $\rho_{\mathrm{g}}=2 \mathrm{~g} \mathrm{~cm}^{-3}$, where $\rho_{\mathrm{g}}$ is the mean density of the grain material (core and ice mantle). To these parameters corresponds a grain surface area per hydrogen nucleus $n_{\mathrm{g}} \sigma_{\mathrm{g}} / n_{\mathrm{H}}=1.1 \times 10^{-21}\left(0.10 / a_{\mathrm{g}}(\mu \mathrm{m})\right) \mathrm{cm}^{2}$.

In Fig. 8, we plot the fractional abundances of the major ions and the free electron abundance against $a_{\mathrm{g}}$, for a density of $n_{\mathrm{H}}=2 \times 10^{6} \mathrm{~cm}^{-3}$ and $T=10 \mathrm{~K}$. As the grain size increases, 


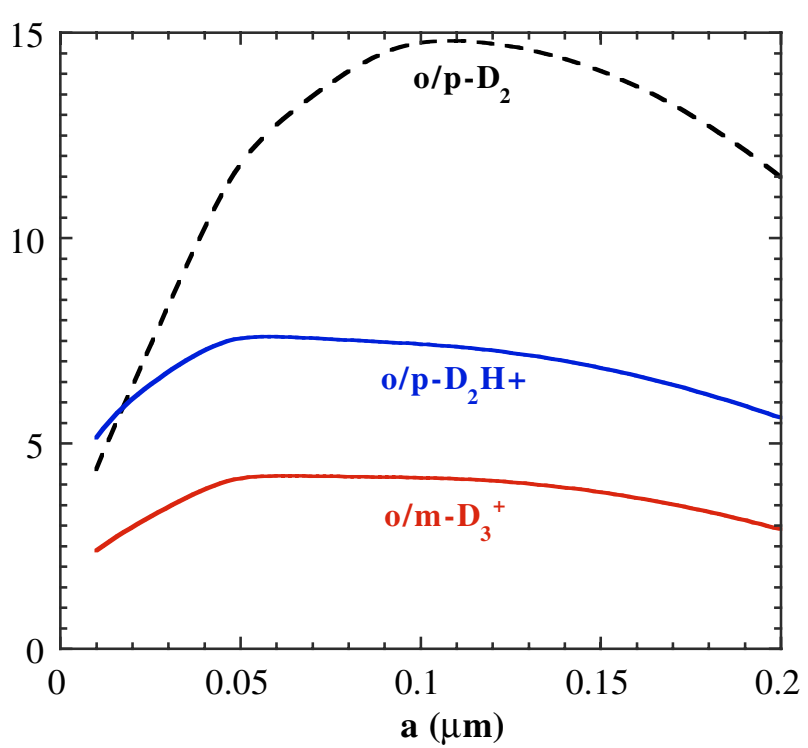

Fig. 9. The ortho/meta ratio of $\mathrm{D}_{3}^{+}$and the ortho/para ratios of $\mathrm{D}_{2} \mathrm{H}^{+}$ and $\mathrm{D}_{2}$ plotted against the grain radius, $a_{\mathrm{g}}$, for a density of $n_{\mathrm{H}}=2 \times$ $10^{6} \mathrm{~cm}^{-3}, T=10 \mathrm{~K}$, and $\zeta=3 \times 10^{-17} \mathrm{~s}^{-1}$.

the number density of grains (more specifically, of negatively charged grains) decreases, and so the free electron fraction increases, as may be seen in Fig. 8. Polyatomic ions recombine rapidly (dissociatively) with free electrons and on the surfaces of negatively charged grains. On the other hand, $\mathrm{H}^{+}$recombines only slowly (radiatively) with free electrons but rapidly on the surfaces of negatively charged grains (which act as a third body and effectively catalyse the recombination reaction). Hence, the fraction of $\mathrm{H}^{+}$increases with $a_{\mathrm{g}}$, and $\mathrm{H}^{+}$becomes the major ion (when $a_{\mathrm{g}} \gtrsim 0.1 \mu \mathrm{m}$, for $n\left(\mathrm{H}_{2}\right)=10^{6} \mathrm{~cm}^{-3}$ and $T=10 \mathrm{~K}$ ). The fraction of polyatomic ions first increases with the grain radius, as the number density of negatively charged grains decreases, then decreases as recombination with free electrons takes over. Thus, $\left[\mathrm{D}_{3}^{+}\right]$has a maximum in the vicinity of $a_{\mathrm{g}}=0.1 \mu \mathrm{m}$. Referring now to Fig. 9, we see that the maximum in $\left[\mathrm{D}_{3}^{+}\right]$is reflected in the variation of the ortho/para $\mathrm{D}_{2}$ ratio. The ortho/para $\mathrm{D}_{2} \mathrm{H}^{+}$and ortho/meta $\mathrm{D}_{3}^{+}$ratios, on the other hand, are approximately constant: they are determined by deuteron exchange with HD, whose fractional abundance is independent of $a_{\mathrm{g}}$ (as well as being independent of $n_{\mathrm{H}}$ ).

\section{Observational perspectives}

We consider in this Section the prospects of observing directly either the ortho/para (ortho/meta) ratios or the relative abundances of the different deuterated forms of $\mathrm{H}_{3}^{+}$. Some pertinent observations have already been made. Vastel et al. (2004) have shown that $\mathrm{H}_{2} \mathrm{D}^{+}$and $\mathrm{D}_{2} \mathrm{H}^{+}$have comparable column densities, of the order of $10^{13} \mathrm{~cm}^{-2}$, in the prestellar core $16293 \mathrm{E}$; this observational result is compatible with the models discussed above. At densities in excess of $10^{6} \mathrm{~cm}^{-3}$, the most abundant ion is likely to be either $\mathrm{D}_{3}^{+}$or $\mathrm{H}^{+}$, depending on the grain size. It follows that the total number density of positive ions is considerably larger than the sum of the abundances of $\mathrm{H}_{2} \mathrm{D}^{+}$ and $\mathrm{D}_{2} \mathrm{H}^{+}$. In particular, a measurement of the fractional abundance of $\mathrm{H}_{2} \mathrm{D}^{+}$provides only a lower limit to the degree of ionization.

$\mathrm{H}_{2} \mathrm{D}^{+}$has been detected recently in the outer parts of the circumstellar disk surrounding the T Tauri star DM Tau (Ceccarelli et al. 2004), and the discussion in the present paper may be relevant to such objects. Once again, the determination of the ionization degree from the observations is complicated by our ignorance of the grain size in the relevant disk layer.

Whilst $\mathrm{H}_{2} \mathrm{D}^{+}$and $\mathrm{D}_{2} \mathrm{H}^{+}$can be (and have been) observed at sub-mm wavelengths, $\mathrm{H}_{3}^{+}$and $\mathrm{D}_{3}^{+}$lack a permanent dipole moment and consequently do not emit detectable rotational transitions. However, vibrational transitions are allowed in both species, and $\mathrm{H}_{3}^{+}$has been observed, in the near infrared, in absorption towards strong background sources (e.g. McCall et al. 1999). Therefore, we have considered the observability, in the near infrared, of the deuterated forms of $\mathrm{H}_{3}^{+}$, assuming that the conditions are similar to those under which $\mathrm{H}_{3}^{+}$itself has been detected. The sub-mm detections of $\mathrm{H}_{2} \mathrm{D}^{+}$and $\mathrm{D}_{2} \mathrm{H}^{+}$yield fractional abundances of the order of $10^{-10}$, assuming a hydrogen column density of the order of $10^{23} \mathrm{~cm}^{-2}$; this value is typical of some prestellar cores (Bacmann et al. 2000) and corresponds to 50 mag of visual extinction, or approximately 2 mag at the wavelengths (around $5 \mu \mathrm{m}$ ) of the lines in Table 3. In this table are given, for several relevant transitions, the computed column density, $N_{\tau=1}$, for absorption from the lower level of a line for which the optical depth at the line centre, $\tau=1$ (see, for example, Eq. (B12) of Tielens \& Hollenbach 1985). We adopted a line width of $1 \mathrm{~km} \mathrm{~s}^{-1}$. In Table 3 we give also the excitation energy, $E_{1}$, of the lower level of the transition, relative to the ground level, and the transition wavelength. The $A$-values and quantum numbers have been taken from Ramanlal \& Tennyson (2004): $\left(J, K_{\mathrm{a}}, K_{\mathrm{c}}\right)$ in the case of $\mathrm{H}_{2} \mathrm{D}^{+}$ and $\mathrm{D}_{2} \mathrm{H}^{+}$; and $\left(v_{1}, v_{2}, J, G, U\right)$ in the case of $\mathrm{D}_{3}^{+}$. We see that the computed column densities are of the order of $10^{14} \mathrm{~cm}^{-2}$, and so several lines of the deuterated forms of $\mathrm{H}_{3}^{+}$might be detectable, with optical depths at the line centre of the order of 0.1 (depending on the line width). Most of the transitions fall outside the $\mathrm{M}$ and $\mathrm{L}$ windows and would be observable only from above the atmosphere. Such observations may be the best way of determining the abundances of the ortho, para and (in the case of $\mathrm{D}_{3}^{+}$) meta forms of the isotopes of $\mathrm{H}_{3}^{+}$.

\section{Appendix A: Additional chemical reactions and their rate coefficients}

In this appendix are specified the additional reactions included to allow for the consequences of Bose-Einstein statistics on the abundances of multiply-deuterated species, as determined by our chemical model. As the abundance of D in the gas-phase can become comparable with that of $\mathrm{H}$, the formation of paraand ortho- $\mathrm{D}_{2}$ on grain surfaces is included in the reaction set, in addition to the formation of para- and ortho- $\mathrm{H}_{2}$ and of HD.

\section{Appendix B: A simplified analysis of the meta/ortho $D_{3}^{+}$abundance ratio}

Meta- $\mathrm{D}_{3}^{+}$and ortho- $\mathrm{D}_{3}^{+}$are produced with approximately equal probability in the reactions $\mathrm{D}_{2} \mathrm{H}^{+}\left(\mathrm{HD}, \mathrm{H}_{2}\right) \mathrm{D}_{3}^{+}$, as may be seen 
Table 3. Requisite column densities for unit optical depth in the absorption line centre for the deuterated forms of $\mathrm{H}_{3}^{+}$. Spectroscopic data from Ramanlal \& Tennyson (2004).

\begin{tabular}{lccccc}
\hline \hline Species & Upper level & Lower level & $\begin{array}{c}E_{l} \\
\left(\mathrm{~cm}^{-1}\right)\end{array}$ & $\begin{array}{c}\text { Wavelength } \\
(\mu \mathrm{m})\end{array}$ & $\begin{array}{c}N_{\tau=1} \\
\left(\mathrm{~cm}^{-2}\right)\end{array}$ \\
\hline $\mathrm{H}_{2} \mathrm{D}^{+}$(para) & $(1,1,1)^{a}$ & $(0,0,0)$ & 0.0 & 4.162 & $1.9 \times 10^{14}$ \\
$\mathrm{H}_{2} \mathrm{D}^{+}$(ortho) & $(0,0,0)$ & $(1,1,1)$ & 60.0 & 4.395 & $6.1 \times 10^{14}$ \\
$\mathrm{H}_{2} \mathrm{D}^{+}$(ortho) & $(2,0,2)$ & $(1,1,1)$ & 60.0 & 4.136 & $7.1 \times 10^{14}$ \\
$\mathrm{H}_{2} \mathrm{D}^{+}$(ortho) & $(2,2,0)$ & $(1,1,1)$ & 60.0 & 3.985 & $4.9 \times 10^{14}$ \\
$\mathrm{D}_{2} \mathrm{H}^{+}$(ortho) & $(1,1,1)$ & $(0,0,0)$ & 0.0 & 4.965 & $4.7 \times 10^{14}$ \\
$\mathrm{D}_{2} \mathrm{H}^{+}$(ortho) & $(1,0,1)$ & $(0,0,0)$ & 0.0 & 4.72 & $5.5 \times 10^{14}$ \\
$\mathrm{D}_{2} \mathrm{H}^{+}$(para) & $(1,1,0)$ & $(1,0,1)$ & 34.9 & 5.02 & $6.9 \times 10^{14}$ \\
$\mathrm{D}_{2} \mathrm{H}^{+}$(para) & $(2,0,2)$ & $(1,0,1)$ & 34.9 & 4.63 & $7.6 \times 10^{14}$ \\
$\mathrm{D}_{3}^{+}$(ortho) & $(0,1,1,0,1)^{b}$ & $(0,0,0,0,0)$ & 0.0 & 5.296 & $2.2 \times 10^{13}$ \\
$\mathrm{D}_{3}^{+}$(meta) & $(0,1,0,1,1)$ & $(0,0,1,1,0)$ & 32.3 & 5.548 & $1.6 \times 10^{14}$ \\
$\mathrm{D}_{3}^{+}$(meta) & $(0,1,2,1,-1)$ & $(0,0,1,1,0)$ & 32.3 & 5.198 & $9.9 \times 10^{13}$ \\
$\mathrm{D}_{3}^{+}$(meta) & $(0,1,2,1,1)$ & $(0,0,1,1,0)$ & 32.3 & 5.166 & $9.1 \times 10^{13}$ \\
$\mathrm{D}_{3}^{+}$(para) & $(0,1,1,0,-1)$ & $(0,0,1,0,0)$ & 43.6 & 5.433 & $4.5 \times 10^{14}$ \\
\hline$a$ & & & & \\
${ }_{b}\left(V_{1}, K_{\mathrm{a}}, K_{\mathrm{c}}\right)$. & & & & &
\end{tabular}

from Appendix A; let us denote the rate coefficient for formation of meta- or ortho- $\mathrm{D}_{3}^{+}$in this reaction by $k_{1}$. In addition, there is interchange between the meta and ortho forms in the forwards (and reverse) reactions meta- $\mathrm{D}_{3}^{+}(\mathrm{HD}, \mathrm{HD})$ ortho- $\mathrm{D}_{3}^{+}$. At low kinetic temperatures, $T$, the reverse reaction, which is endoergic by $46.5 \mathrm{~K}$, may be neglected; the rate coefficient for the forwards reaction is $k_{2}=2.8 \times 10^{-10} \mathrm{~cm}^{3} \mathrm{~s}^{-1}$.

Both meta- $\mathrm{D}_{3}^{+}$and ortho- $\mathrm{D}_{3}^{+}$are destroyed in dissociative recombination with electrons or on the surfaces of grains. We neglect the latter process (an assumption whose validity increases with the grain size); for the former process, we have $k_{3}=2.7 \times 10^{-8}(T / 300)^{-0.52} \mathrm{~cm}^{3} \mathrm{~s}^{-1}$ (cf. Appendix A). Furthermore, meta- $\mathrm{D}_{3}^{+}$can be removed even at low $T$ by the reaction meta- $\mathrm{D}_{3}^{+}$(ortho- $\mathrm{H}_{2}, \mathrm{HD}$ )ortho- $\mathrm{D}_{2} \mathrm{H}^{+}$; the rate coefficient is $k_{4}=5.0 \times 10^{-10} \exp (-18.0 / T)$. In steady state, the density of ortho- $\mathrm{D}_{3}^{+}$is determined by

$\left[k_{1} n\left(\mathrm{D}_{2} \mathrm{H}^{+}\right)+k_{2} n\left(\operatorname{meta} \mathrm{D}_{3}^{+}\right)\right] n(\mathrm{HD})=k_{3} n_{\mathrm{e}} n\left(\right.$ ortho $\left.\mathrm{D}_{3}^{+}\right)$

and that of meta- $\mathrm{D}_{3}^{+}$by

$k_{1} n\left(\mathrm{D}_{2} \mathrm{H}^{+}\right) n(\mathrm{HD})=\left[k_{3} n_{\mathrm{e}}+k_{2} n(\mathrm{HD})\right.$

$$
\left.\left.+k_{4} n \text { (ortho } \mathrm{H}_{2}\right)\right] n\left(\text { meta }_{3}^{+}\right) \text {. }
$$

Eliminating $n\left(\mathrm{D}_{2} \mathrm{H}^{+}\right)$between these relations yields

$\frac{n\left(\operatorname{meta~}_{3}^{+}\right)}{n\left(\text { ortho } \mathrm{D}_{3}^{+}\right)}=\frac{k_{3} n_{\mathrm{e}}}{k_{3} n_{\mathrm{e}}+2 k_{2} n(\mathrm{HD})+k_{4} n\left(\text { ortho } \mathrm{H}_{2}\right)}$.

Taking $T=10 \mathrm{~K}, n\left(\mathrm{H}_{2}\right)=10^{6} \mathrm{~cm}^{-3}, a_{\mathrm{g}}=0.1 \mu \mathrm{m}$, as in the reference model, we have $n(\mathrm{HD})=3.2 \times 10^{-5} n\left(\mathrm{H}_{2}\right)$, $n_{\mathrm{e}} \approx 10^{-8} n\left(\mathrm{H}_{2}\right), n\left(\right.$ ortho $\left.\mathrm{H}_{2}\right)=5 \times 10^{-5} n\left(\mathrm{H}_{2}\right)$ and hence $n\left(\right.$ meta $\left.\mathrm{D}_{3}^{+}\right) / n\left(\right.$ ortho $\left.\mathrm{D}_{3}^{+}\right) \approx 0.07$, which is in reasonable agreement with the results presented in Fig. 5.
Thus, at low temperatures, the meta/ortho $\mathrm{D}_{3}^{+}$ratio is expected to be less than 1 , by an amount which depends on the degree of ionization and the ortho/para $\mathrm{H}_{2}$ ratio. The analogous derivation of the para/ortho $\mathrm{D}_{2} \mathrm{H}^{+}$ratio would yield a qualitatively similar result.

Acknowledgements. It is a pleasure to thank Eric Herbst for informative discussions relating directly to the subject of the present study and Jonathan Tennyson for very helpful e-mail correspondence and providing results in advance of publication. We are also grateful to Paola Caselli, for her comments on the original version of our paper, and to Tom Millar, who was a helpful referee.

\section{References}

Bacmann, A., André, P., Puget, J.-L., et al. 2000, A\&A, 361, 555

Caselli, P., van der Tak, F. F. S., Ceccarelli, C., \& Bacmann, A. 2003, A\&A, 403, L37

Ceccarelli, C., Dominik, C., Lefloch, B., Caselli, P., \& Caux, E. 2004, ApJ, 607, L51

Herzberg, G. 1950, Spectra of Diatomic Molecules (Princeton, NJ: D. Van Nostrand)

McCall, B. J., Geballe, T. R., Hinkle, K. H., \& Oka, T. 1999, ApJ, 522, 338

Mizuno, A., Fukui, Y., Iwata, T., Nozawa, S., \& Takano, T. 1990, ApJ, 356, 184

Polyansky, O. L., \& Tennyson, J. 1999, J. Chem. Phys., 110, 5056

Ramanlal, J., \& Tennyson, J. 2004, MNRAS, 354, 161

Ramanlal, J., Polyansky, O. L., \& Tennyson, J. 2003, A\&A, 406, 383

Roberts, H., Herbst, E., \& Millar, T. J. 2003, ApJ, 591, L41

Stark, R., Sandell, G., Beck, S. C., et al. 2004, ApJ, 608, 341

Townes, C. H., \& Schawlow, A. L. 1955, Microwave Spectroscopy (London: McGraw-Hill)

Vastel, C., Phillips, T. G., \& Yoshida, H. 2004, ApJ, 606, L127

Walmsley, C. M., Flower, D. R., \& Pineau des Forêts, G. 2004, A\&A, 418,1035 
D. R. Flower et al.: Multiply-deuterated species in prestellar cores, Online Material $p 1$

\section{Online Material}


Table A.1. Rate coefficients adopted in our chemical model for the reactions relating to the meta, ortho and para forms of multiplydeuterated species. The parameters $\alpha, \beta$, and $\gamma$ define the rate coefficients $k\left(\mathrm{~cm}^{3} \mathrm{~s}^{-1}\right)$ at temperature $T$ through the relation $k=$ $\tilde{J}\left(a_{\mathrm{g}}, T\right) \gamma(T / 300)^{\alpha} \exp (-\beta / T) ; \tilde{J}$ allows for Coulomb focusing in reactions of positive ions and negatively charged grains (Draine $\&$ Sutin 1987, Eq. (3.4)); $a_{\mathrm{g}}=0.1 \mu \mathrm{m}$ is adopted in the table. The rates $\left(\mathrm{s}^{-1}\right)$ of reactions induced directly by cosmic rays (crp) are given by $\gamma \zeta$, where $\zeta$ is the rate of cosmic ray ionization of $\mathrm{H}_{2}$. "g" denotes "grain", "m", "o" and "p" denote "meta", "ortho" and "para", respectively. Key reactions are in bold face. Numbers in parentheses are powers of 10. (The present table is complementary to that in Appendix A of Walmsley et al. 2004.)

\begin{tabular}{|c|c|c|c|}
\hline Reaction & $\gamma$ & $\overline{\alpha \alpha}$ & $\overline{\bar{\beta}}$ \\
\hline $\mathrm{D}+\mathrm{D} \rightarrow \mathrm{D}_{2}(\mathrm{p})$ & 0.33 & & \\
\hline $\mathrm{D}+\mathrm{D} \rightarrow \mathrm{D}_{2}(\mathrm{o})$ & 0.67 & & \\
\hline $\mathrm{D}_{2}(\mathrm{p})+\operatorname{crp} \rightarrow \mathrm{D}^{+}+\mathrm{D}+\mathrm{e}^{-}$ & 0.04 & & \\
\hline $\mathrm{D}_{2}(\mathrm{p})+\operatorname{crp} \rightarrow \mathrm{D}+\mathrm{D}$ & 1.50 & & \\
\hline $\mathrm{D}_{2}(\mathrm{p})+\operatorname{crp} \rightarrow \mathrm{D}_{2}^{+}(\mathrm{p})+\mathrm{e}^{-}$ & 0.96 & & \\
\hline $\mathrm{D}_{2}(\mathrm{o})+\operatorname{crp} \rightarrow \mathrm{D}^{+}+\mathrm{D}+\mathrm{e}^{-}$ & 0.04 & & \\
\hline $\mathrm{D}_{2}(\mathrm{o})+\operatorname{crp} \rightarrow \mathrm{D}+\mathrm{D}$ & 1.50 & & \\
\hline $\mathrm{D}_{2}(\mathrm{o})+\operatorname{crp} \rightarrow \mathrm{D}_{2}^{+}(\mathrm{o})+\mathrm{e}^{-}$ & 0.96 & & \\
\hline $\mathrm{H}^{+}+\mathrm{D}_{2}(\mathrm{p}) \rightarrow \mathrm{D}^{+}+\mathrm{HD}$ & $2.10(-09)$ & 0.00 & 405.0 \\
\hline $\mathrm{H}^{+}+\mathrm{D}_{2}(\mathrm{o}) \rightarrow \mathrm{D}^{+}+\mathrm{HD}$ & $2.10(-09)$ & 0.00 & 491.0 \\
\hline $\mathrm{D}^{+}+\mathrm{HD} \rightarrow \mathrm{H}^{+}+\mathrm{D}_{2}(\mathrm{p})$ & $0.50(-09)$ & 0.00 & 0.0 \\
\hline $\mathrm{D}^{+}+\mathrm{HD} \rightarrow \mathrm{H}^{+}+\mathrm{D}_{2}(\mathrm{o})$ & $0.50(-09)$ & 0.00 & 0.0 \\
\hline $\mathrm{D}_{2}{ }^{+}(\mathrm{p})+\mathrm{H}_{2}(\mathrm{p}) \rightarrow \mathrm{H}_{2} \mathrm{D}^{+}(\mathrm{p})+\mathrm{D}$ & $1.05(-09)$ & 0.00 & 0.0 \\
\hline $\mathrm{D}_{2}^{+}(\mathrm{o})+\mathrm{H}_{2}(\mathrm{p}) \rightarrow \mathrm{H}_{2} \mathrm{D}^{+}(\mathrm{p})+\mathrm{D}$ & $1.05(-09)$ & 0.00 & 0.0 \\
\hline $\mathrm{D}_{2}^{+}(\mathrm{p})+\mathrm{H}_{2}(\mathrm{o}) \rightarrow \mathrm{H}_{2} \mathrm{D}^{+}(\mathrm{o})+\mathrm{D}$ & $1.05(-09)$ & 0.00 & 0.0 \\
\hline $\mathrm{D}_{2}^{+}(\mathrm{o})+\mathrm{H}_{2}(\mathrm{o}) \rightarrow \mathrm{H}_{2} \mathrm{D}^{+}(\mathrm{o})+\mathrm{D}$ & $1.05(-09)$ & 0.00 & 0.0 \\
\hline $\mathrm{D}_{2}^{+}(\mathrm{p})+\mathrm{H}_{2}(\mathrm{p}) \rightarrow \mathrm{D}_{2} \mathrm{H}^{+}(\mathrm{p})+\mathrm{H}$ & $1.05(-09)$ & 0.00 & 0.0 \\
\hline $\mathrm{D}_{2}^{+}(\mathrm{o})+\mathrm{H}_{2}(\mathrm{p}) \rightarrow \mathrm{D}_{2} \mathrm{H}^{+}(\mathrm{o})+\mathrm{H}$ & $1.05(-09)$ & 0.00 & 0.0 \\
\hline $\mathrm{D}_{2}^{+}(\mathrm{p})+\mathrm{H}_{2}(\mathrm{o}) \rightarrow \mathrm{D}_{2} \mathrm{H}^{+}(\mathrm{p})+\mathrm{H}$ & $1.05(-09)$ & 0.00 & 0.0 \\
\hline $\mathrm{D}_{2}^{+}(\mathrm{o})+\mathrm{H}_{2}(\mathrm{o}) \rightarrow \mathrm{D}_{2} \mathrm{H}^{+}(\mathrm{o})+\mathrm{H}$ & $1.05(-09)$ & 0.00 & 0.0 \\
\hline $\mathrm{H}_{2}^{+}(\mathrm{p})+\mathrm{D}_{2}(\mathrm{p}) \rightarrow \mathrm{H}_{2} \mathrm{D}^{+}(\mathrm{p})+\mathrm{D}$ & $1.05(-09)$ & 0.00 & 0.0 \\
\hline $\mathrm{H}_{2}^{+}(\mathrm{p})+\mathrm{D}_{2}(\mathrm{o}) \rightarrow \mathrm{H}_{2} \mathrm{D}^{+}(\mathrm{p})+\mathrm{D}$ & $1.05(-09)$ & 0.00 & 0.0 \\
\hline $\mathrm{H}_{2}^{+}(\mathrm{o})+\mathrm{D}_{2}(\mathrm{p}) \rightarrow \mathrm{H}_{2} \mathrm{D}^{+}(\mathrm{o})+\mathrm{D}$ & $1.05(-09)$ & 0.00 & 0.0 \\
\hline $\mathrm{H}_{2}^{+}(\mathrm{o})+\mathrm{D}_{2}(\mathrm{o}) \rightarrow \mathrm{H}_{2} \mathrm{D}^{+}(\mathrm{o})+\mathrm{D}$ & $1.05(-09)$ & 0.00 & 0.0 \\
\hline $\mathrm{H}_{2}^{+}(\mathrm{p})+\mathrm{D}_{2}(\mathrm{p}) \rightarrow \mathrm{D}_{2} \mathrm{H}^{+}(\mathrm{p})+\mathrm{H}$ & $1.05(-09)$ & 0.00 & 0.0 \\
\hline $\mathrm{H}_{2}^{+}(\mathrm{p})+\mathrm{D}_{2}(\mathrm{o}) \rightarrow \mathrm{D}_{2} \mathrm{H}^{+}(\mathrm{o})+\mathrm{H}$ & $1.05(-09)$ & 0.00 & 0.0 \\
\hline $\mathrm{H}_{2}{ }^{+}(\mathrm{o})+\mathrm{D}_{2}(\mathrm{p}) \rightarrow \mathrm{D}_{2} \mathrm{H}^{+}(\mathrm{p})+\mathrm{H}$ & $1.05(-09)$ & 0.00 & 0.0 \\
\hline $\mathrm{H}_{2}^{+}(\mathrm{o})+\mathrm{D}_{2}(\mathrm{o}) \rightarrow \mathrm{D}_{2} \mathrm{H}^{+}(\mathrm{o})+\mathrm{H}$ & $1.05(-09)$ & 0.00 & 0.0 \\
\hline $\mathrm{HD}^{+}+\mathrm{HD} \rightarrow \mathrm{H}_{2} \mathrm{D}^{+}(\mathrm{p})+\mathrm{D}$ & $5.25(-10)$ & 0.00 & 0.0 \\
\hline $\mathrm{HD}^{+}+\mathrm{HD} \rightarrow \mathrm{H}_{2} \mathrm{D}^{+}(\mathrm{o})+\mathrm{D}$ & $5.25(-10)$ & 0.00 & 0.0 \\
\hline $\mathrm{HD}^{+}+\mathrm{HD} \rightarrow \mathrm{D}_{2} \mathrm{H}^{+}(\mathrm{p})+\mathrm{H}$ & $5.25(-10)$ & 0.00 & 0.0 \\
\hline $\mathrm{HD}^{+}+\mathrm{HD} \rightarrow \mathrm{D}_{2} \mathrm{H}^{+}(\mathrm{o})+\mathrm{H}$ & $5.25(-10)$ & 0.00 & 0.0 \\
\hline $\mathrm{H}_{2} \mathrm{D}^{+}(\mathrm{p})+\mathrm{D} \rightarrow \mathrm{D}_{2} \mathrm{H}^{+}(\mathrm{p})+\mathrm{H}$ & $0.50(-09)$ & 0.00 & 0.0 \\
\hline $\mathrm{H}_{2} \mathrm{D}^{+}(\mathrm{p})+\mathrm{D} \rightarrow \mathrm{D}_{2} \mathrm{H}^{+}(\mathrm{o})+\mathrm{H}$ & $0.50(-09)$ & 0.00 & 0.0 \\
\hline $\mathrm{H}_{2} \mathrm{D}^{+}(\mathrm{o})+\mathrm{D} \rightarrow \mathrm{D}_{2} \mathrm{H}^{+}(\mathrm{p})+\mathrm{H}$ & $0.50(-09)$ & 0.00 & 0.0 \\
\hline $\mathrm{H}_{2} \mathrm{D}^{+}(\mathrm{o})+\mathrm{D} \rightarrow \mathrm{D}_{2} \mathrm{H}^{+}(\mathrm{o})+\mathrm{H}$ & $0.50(-09)$ & 0.00 & 0.0 \\
\hline $\mathrm{D}_{2} \mathrm{H}^{+}(\mathrm{p})+\mathrm{H} \rightarrow \mathrm{H}_{2} \mathrm{D}^{+}(\mathrm{p})+\mathrm{D}$ & $1.00(-09)$ & 0.00 & 0.0 \\
\hline $\mathrm{D}_{2} \mathrm{H}^{+}(\mathrm{o})+\mathrm{H} \rightarrow \mathrm{H}_{2} \mathrm{D}^{+}(\mathrm{p})+\mathrm{D}$ & $1.00(-09)$ & 0.00 & 600.0 \\
\hline $\mathrm{D}_{2} \mathrm{H}^{+}(\mathrm{p})+\mathrm{H} \rightarrow \mathrm{H}_{2} \mathrm{D}^{+}(\mathrm{o})+\mathrm{D}$ & $1.00(-09)$ & 0.00 & 463.3 \\
\hline $\mathrm{D}_{2} \mathrm{H}^{+}(\mathrm{o})+\mathrm{H} \rightarrow \mathrm{H}_{2} \mathrm{D}^{+}(\mathrm{o})+\mathrm{D}$ & $1.00(-09)$ & 0.00 & 513.5 \\
\hline $\mathrm{H}_{3}{ }^{+}(\mathrm{o})+\mathrm{D}_{2}(\mathrm{p}) \rightarrow \mathrm{H}_{2} \mathrm{D}^{+}(\mathrm{o})+\mathrm{HD}$ & $3.50(-10)$ & 0.00 & 0.0 \\
\hline $\mathrm{H}_{3}{ }^{+}(\mathrm{o})+\mathrm{D}_{2}(\mathrm{o}) \rightarrow \mathrm{H}_{2} \mathrm{D}^{+}(\mathrm{o})+\mathrm{HD}$ & $3.50(-10)$ & 0.00 & 0.0 \\
\hline $\mathrm{H}_{3}^{+}(\mathrm{o})+\mathrm{D}_{2}(\mathrm{p}) \rightarrow \mathrm{D}_{2} \mathrm{H}^{+}(\mathrm{p})+\mathrm{H}_{2}(\mathrm{o})$ & $3.50(-10)$ & 0.00 & 0.0 \\
\hline $\mathrm{H}_{3}^{+}(\mathrm{o})+\mathrm{D}_{2}(\mathrm{o}) \rightarrow \mathrm{D}_{2} \mathrm{H}^{+}(\mathrm{o})+\mathrm{H}_{2}(\mathrm{o})$ & $3.50(-10)$ & 0.00 & 0.0 \\
\hline $\mathrm{H}_{3}{ }^{+}(\mathrm{p})+\mathrm{D}_{2}(\mathrm{p}) \rightarrow \mathrm{D}_{2} \mathrm{H}^{+}(\mathrm{p})+\mathrm{H}_{2}(\mathrm{p})$ & $2.33(-10)$ & 0.00 & 0.0 \\
\hline $\mathrm{H}_{3}^{+}(\mathrm{p})+\mathrm{D}_{2}(\mathrm{o}) \rightarrow \mathrm{D}_{2} \mathrm{H}^{+}(\mathrm{o})+\mathrm{H}_{2}(\mathrm{p})$ & $2.33(-10)$ & 0.00 & 0.0 \\
\hline
\end{tabular}

Table A.1. continued.

\begin{tabular}{|c|c|c|c|}
\hline Reaction & $\bar{\gamma}$ & $\bar{\alpha}$ & $\overline{\beta \beta}$ \\
\hline $\mathrm{H}_{3}{ }^{+}(\mathrm{p})+\mathrm{D}_{2}(\mathrm{p}) \rightarrow \mathrm{D}_{2} \mathrm{H}^{+}(\mathrm{p})+\mathrm{H}_{2}(\mathrm{o})$ & $1.17(-10)$ & 0.00 & 0.0 \\
\hline $\mathrm{H}_{3}^{+}(\mathrm{p})+\mathrm{D}_{2}(\mathrm{o}) \rightarrow \mathrm{D}_{2} \mathrm{H}^{+}(\mathrm{o})+\mathrm{H}_{2}(\mathrm{o})$ & $1.17(-10)$ & 0.00 & 0.0 \\
\hline $\mathrm{H}_{3}{ }^{+}(\mathrm{p})+\mathrm{D}_{2}(\mathrm{p}) \rightarrow \mathrm{H}_{2} \mathrm{D}^{+}(\mathrm{p})+\mathrm{HD}$ & $2.33(-10)$ & 0.00 & 0.0 \\
\hline $\mathrm{H}_{3}{ }^{+}(\mathrm{p})+\mathrm{D}_{2}(\mathrm{o}) \rightarrow \mathrm{H}_{2} \mathrm{D}^{+}(\mathrm{p})+\mathrm{HD}$ & $2.33(-10)$ & 0.00 & 0.0 \\
\hline $\mathrm{H}_{3}{ }^{+}(\mathrm{p})+\mathrm{D}_{2}(\mathrm{p}) \rightarrow \mathrm{H}_{2} \mathrm{D}^{+}(\mathrm{o})+\mathrm{HD}$ & $1.17(-10)$ & 0.00 & 0.0 \\
\hline $\mathrm{H}_{3}{ }^{+}(\mathrm{p})+\mathrm{D}_{2}(\mathrm{o}) \rightarrow \mathrm{H}_{2} \mathrm{D}^{+}(\mathrm{o})+\mathrm{HD}$ & $1.17(-10)$ & 0.00 & 0.0 \\
\hline $\mathbf{H}_{2} \mathbf{D}^{+}(\mathbf{p})+\mathbf{H D} \rightarrow \mathbf{D}_{2} \mathbf{H}^{+}(\mathbf{p})+\mathbf{H}_{2}(\mathbf{p})$ & $1.30(-10)$ & 0.00 & 0.0 \\
\hline $\mathbf{H}_{2} \mathbf{D}^{+}(\mathbf{p})+\mathbf{H D} \rightarrow \mathbf{D}_{2} \mathbf{H}^{+}(\mathbf{o})+\mathbf{H}_{2}(\mathbf{p})$ & $1.30(-10)$ & 0.00 & 0.0 \\
\hline $\mathbf{H}_{2} \mathbf{D}^{+}(\mathbf{o})+\mathbf{H D} \rightarrow \mathbf{D}_{2} \mathbf{H}^{+}(\mathbf{p})+\mathbf{H}_{2}(\mathbf{o})$ & $1.30(-10)$ & 0.00 & 0.0 \\
\hline $\mathbf{H}_{2} \mathbf{D}^{+}(\mathbf{o})+\mathbf{H D} \rightarrow \mathrm{D}_{2} \mathrm{H}^{+}(\mathbf{o})+\mathrm{H}_{2}(\mathbf{o})$ & $1.30(-10)$ & 0.00 & 0.0 \\
\hline $\mathrm{H}_{2} \mathrm{D}^{+}(\mathrm{o})+\mathrm{HD} \rightarrow \mathrm{H}_{3}{ }^{+}(\mathrm{o})+\mathrm{D}_{2}(\mathrm{o})$ & $0.65(-10)$ & 0.00 & 108.0 \\
\hline $\mathrm{H}_{2} \mathrm{D}^{+}(\mathrm{o})+\mathrm{HD} \rightarrow \mathrm{H}_{3}^{+}(\mathrm{o})+\mathrm{D}_{2}(\mathrm{p})$ & $0.65(-10)$ & 0.00 & 194.0 \\
\hline $\mathrm{H}_{2} \mathrm{D}^{+}(\mathrm{o})+\mathrm{HD} \rightarrow \mathrm{H}_{3}^{+}(\mathrm{p})+\mathrm{D}_{2}(\mathrm{o})$ & $0.65(-10)$ & 0.00 & 66.5 \\
\hline $\mathrm{H}_{2} \mathrm{D}^{+}(\mathrm{o})+\mathrm{HD} \rightarrow \mathrm{H}_{3}^{+}(\mathrm{p})+\mathrm{D}_{2}(\mathrm{p})$ & $0.65(-10)$ & 0.00 & 152.5 \\
\hline $\mathrm{H}_{2} \mathrm{D}^{+}(\mathrm{p})+\mathrm{HD} \rightarrow \mathrm{H}_{3}^{+}(\mathrm{p})+\mathrm{D}_{2}(\mathrm{o})$ & $1.30(-10)$ & 0.00 & 153.0 \\
\hline $\mathrm{H}_{2} \mathrm{D}^{+}(\mathrm{p})+\mathrm{HD} \rightarrow \mathrm{H}_{3}{ }^{+}(\mathrm{p})+\mathrm{D}_{2}(\mathrm{p})$ & $1.30(-10)$ & 0.00 & 239.2 \\
\hline $\mathrm{D}_{2} \mathrm{H}^{+}(\mathrm{o})+\mathrm{H}_{2}(\mathrm{p}) \rightarrow \mathrm{H}_{2} \mathrm{D}^{+}(\mathrm{p})+\mathrm{HD}$ & $1.00(-10)$ & 0.00 & 187.2 \\
\hline $\mathrm{D}_{2} \mathrm{H}^{+}(\mathrm{p})+\mathrm{H}_{2}(\mathrm{p}) \rightarrow \mathrm{H}_{2} \mathrm{D}^{+}(\mathrm{p})+\mathrm{HD}$ & $1.00(-10)$ & 0.00 & 137.2 \\
\hline $\mathrm{D}_{2} \mathrm{H}^{+}(\mathrm{o})+\mathrm{H}_{2}(\mathrm{p}) \rightarrow \mathrm{H}_{2} \mathrm{D}^{+}(\mathrm{o})+\mathrm{HD}$ & $1.00(-10)$ & 0.00 & 274.2 \\
\hline $\mathrm{D}_{2} \mathrm{H}^{+}(\mathrm{p})+\mathrm{H}_{2}(\mathrm{p}) \rightarrow \mathrm{H}_{2} \mathrm{D}^{+}(\mathrm{o})+\mathrm{HD}$ & $1.00(-10)$ & 0.00 & 224.2 \\
\hline $\mathrm{D}_{2} \mathrm{H}^{+}(\mathrm{o})+\mathrm{H}_{2}(\mathrm{o}) \rightarrow \mathrm{H}_{2} \mathrm{D}^{+}(\mathrm{o})+\mathrm{HD}$ & $1.00(-10)$ & 0.00 & 103.2 \\
\hline $\mathrm{D}_{2} \mathrm{H}^{+}(\mathrm{p})+\mathrm{H}_{2}(\mathrm{o}) \rightarrow \mathrm{H}_{2} \mathrm{D}^{+}(\mathrm{o})+\mathrm{HD}$ & $1.00(-10)$ & 0.00 & 53.2 \\
\hline $\mathrm{D}_{2} \mathrm{H}^{+}(\mathrm{o})+\mathrm{H}_{2}(\mathrm{o}) \rightarrow \mathrm{H}_{2} \mathrm{D}^{+}(\mathrm{p})+\mathrm{HD}$ & $1.00(-10)$ & 0.00 & 17.3 \\
\hline $\mathrm{D}_{2} \mathrm{H}^{+}(\mathrm{p})+\mathrm{H}_{2}(\mathrm{o}) \rightarrow \mathrm{H}_{2} \mathrm{D}^{+}(\mathrm{p})+\mathrm{HD}$ & $1.00(-10)$ & 0.00 & 0.0 \\
\hline $\mathrm{D}_{2} \mathrm{H}^{+}(\mathrm{o})+\mathrm{H}_{2}(\mathrm{p}) \rightarrow \mathrm{H}_{3}^{+}(\mathrm{p})+\mathrm{D}_{2}(\mathrm{o})$ & $2.00(-10)$ & 0.00 & 340.2 \\
\hline $\mathrm{D}_{2} \mathrm{H}^{+}(\mathrm{p})+\mathrm{H}_{2}(\mathrm{p}) \rightarrow \mathrm{H}_{3}^{+}(\mathrm{p})+\mathrm{D}_{2}(\mathrm{p})$ & $2.00(-10)$ & 0.00 & 375.9 \\
\hline $\mathrm{D}_{2} \mathrm{H}^{+}(\mathrm{o})+\mathrm{H}_{2}(\mathrm{o}) \rightarrow \mathrm{H}_{3}^{+}(\mathrm{p})+\mathrm{D}_{2}(\mathrm{o})$ & $1.00(-10)$ & 0.00 & 169.7 \\
\hline $\mathrm{D}_{2} \mathrm{H}^{+}(\mathrm{p})+\mathrm{H}_{2}(\mathrm{o}) \rightarrow \mathrm{H}_{3}{ }^{+}(\mathrm{p})+\mathrm{D}_{2}(\mathrm{p})$ & $1.00(-10)$ & 0.00 & 205.4 \\
\hline $\mathrm{D}_{2} \mathrm{H}^{+}(\mathrm{p})+\mathrm{H}_{2}(\mathrm{o}) \rightarrow \mathrm{H}_{3}^{+}(\mathrm{o})+\mathrm{D}_{2}(\mathrm{p})$ & $1.00(-10)$ & 0.00 & 238.3 \\
\hline $\mathbf{D}_{2} \mathbf{H}^{+}(\mathbf{o})+\mathbf{H D} \rightarrow \mathbf{D}_{2} \mathbf{H}^{+}(\mathbf{p})+\mathbf{H D}$ & $0.66(-09)$ & 0.00 & 50.2 \\
\hline $\mathbf{D}_{2} \mathbf{H}^{+}(\mathbf{p})+\mathbf{H D} \rightarrow \mathrm{D}_{2} \mathrm{H}^{+}(\mathbf{o})+\mathrm{HD}$ & $0.44(-09)$ & 0.00 & 0.0 \\
\hline $\mathrm{He}^{+}+\mathrm{D}_{2}(\mathrm{p}) \rightarrow \mathrm{D}^{+}+\mathrm{D}+\mathrm{He}$ & $1.10(-13)$ & -.24 & 0.0 \\
\hline $\mathrm{He}^{+}+\mathrm{D}_{2}(\mathrm{o}) \rightarrow \mathrm{D}^{+}+\mathrm{D}+\mathrm{He}$ & $1.10(-13)$ & -.24 & 0.0 \\
\hline $\mathrm{He}^{+}+\mathrm{D}_{2}(\mathrm{p}) \rightarrow \mathrm{D}_{2}^{+}(\mathrm{p})+\mathrm{He}$ & $2.50(-14)$ & 0.00 & 0.0 \\
\hline $\mathrm{He}^{+}+\mathrm{D}_{2}(\mathrm{o}) \rightarrow \mathrm{D}_{2}^{+}(\mathrm{o})+\mathrm{He}$ & $2.50(-14)$ & 0.00 & 0.0 \\
\hline $\mathrm{D}_{2}^{+}(\mathrm{p})+\mathrm{e}^{-} \rightarrow \mathrm{D}+\mathrm{D}$ & $3.40(-09)$ & -.40 & 0.0 \\
\hline $\mathrm{D}_{2}^{+}(\mathrm{o})+\mathrm{e}^{-} \rightarrow \mathrm{D}+\mathrm{D}$ & $3.40(-09)$ & -.40 & 0.0 \\
\hline $\mathrm{D}_{2} \mathrm{H}^{+}(\mathrm{o})+\mathrm{e}^{-} \rightarrow \mathrm{D}+\mathrm{D}+\mathrm{H}$ & $4.96(-08)$ & -.52 & 0.0 \\
\hline $\mathrm{D}_{2} \mathrm{H}^{+}(\mathrm{p})+\mathrm{e}^{-} \rightarrow \mathrm{D}+\mathrm{D}+\mathrm{H}$ & $4.96(-08)$ & -.52 & 0.0 \\
\hline $\mathrm{D}_{2} \mathrm{H}^{+}(\mathrm{o})+\mathrm{e}^{-} \rightarrow \mathrm{HD}+\mathrm{D}$ & $1.36(-08)$ & -.52 & 0.0 \\
\hline $\mathrm{D}_{2} \mathrm{H}^{+}(\mathrm{p})+\mathrm{e}^{-} \rightarrow \mathrm{HD}+\mathrm{D}$ & $1.36(-08)$ & -.52 & 0.0 \\
\hline $\mathrm{D}_{2} \mathrm{H}^{+}(\mathrm{o})+\mathrm{e}^{-} \rightarrow \mathrm{D}_{2}(\mathrm{o})+\mathrm{H}$ & $4.76(-09)$ & -.52 & 0.0 \\
\hline $\mathrm{D}_{2} \mathrm{H}^{+}(\mathrm{p})+\mathrm{e}^{-} \rightarrow \mathrm{D}_{2}(\mathrm{p})+\mathrm{H}$ & $4.76(-09)$ & -.52 & 0.0 \\
\hline $\mathrm{D}_{2}^{+}(\mathrm{o})+\mathrm{H} \rightarrow \mathrm{H}^{+}+\mathrm{D}_{2}(\mathrm{o})$ & $6.40(-10)$ & 0.00 & 0.0 \\
\hline $\mathrm{D}_{2}^{+}(\mathrm{p})+\mathrm{H} \rightarrow \mathrm{H}^{+}+\mathrm{D}_{2}(\mathrm{p})$ & $6.40(-10)$ & 0.00 & 0.0 \\
\hline $\mathrm{HD}^{+}+\mathrm{D} \rightarrow \mathrm{D}^{+}+\mathrm{HD}$ & $6.40(-10)$ & 0.00 & 0.0 \\
\hline $\mathrm{HD}^{+}+\mathrm{D} \rightarrow \mathrm{D}_{2}^{+}(\mathrm{p})+\mathrm{H}$ & $0.50(-09)$ & 0.00 & 0.0 \\
\hline $\mathrm{HD}^{+}+\mathrm{D} \rightarrow \mathrm{D}_{2}^{+}(\mathrm{o})+\mathrm{H}$ & $0.50(-09)$ & 0.00 & 0.0 \\
\hline $\mathrm{D}_{2}{ }^{+}(\mathrm{p})+\mathrm{H} \rightarrow \mathrm{HD}^{+}+\mathrm{D}$ & $1.00(-09)$ & 0.00 & 430.0 \\
\hline $\mathrm{D}_{2}^{+}(\mathrm{o})+\mathrm{H} \rightarrow \mathrm{HD}^{+}+\mathrm{D}$ & $1.00(-09)$ & 0.00 & 472.0 \\
\hline $\mathrm{D}_{2}^{+}(\mathrm{o})+\mathrm{D} \rightarrow \mathrm{D}^{+}+\mathrm{D}_{2}(\mathrm{o})$ & $6.40(-10)$ & 0.00 & 0.0 \\
\hline $\mathrm{D}_{2}^{+}(\mathrm{p})+\mathrm{D} \rightarrow \mathrm{D}^{+}+\mathrm{D}_{2}(\mathrm{p})$ & $6.40(-10)$ & 0.00 & 0.0 \\
\hline $\mathrm{D}_{2}{ }^{+}(\mathrm{o})+\mathrm{HD} \rightarrow \mathrm{D}_{2} \mathrm{H}^{+}(\mathrm{o})+\mathrm{D}$ & $1.05(-09)$ & 0.00 & 0.0 \\
\hline $\mathrm{D}_{2}{ }^{+}(\mathrm{p})+\mathrm{HD} \rightarrow \mathrm{D}_{2} \mathrm{H}^{+}(\mathrm{p})+\mathrm{D}$ & $1.05(-09)$ & 0.00 & 0.0 \\
\hline $\mathrm{D}_{2}^{+}(\mathrm{o})+\mathrm{HD} \rightarrow \mathrm{D}_{3}^{+}(\mathrm{m})+\mathrm{H}$ & $5.25(-10)$ & 0.00 & 0.0 \\
\hline $\mathrm{D}_{2}^{+}(\mathrm{o})+\mathrm{HD} \rightarrow \mathrm{D}_{3}^{+}(\mathrm{o})+\mathrm{H}$ & $5.25(-10)$ & 0.00 & 0.0 \\
\hline $\mathrm{D}_{2}{ }^{+}(\mathrm{p})+\mathrm{HD} \rightarrow \mathrm{D}_{3}{ }^{+}(\mathrm{m})+\mathrm{H}$ & $1.05(-09)$ & 0.00 & 0.0 \\
\hline
\end{tabular}


Table A.1. continued.

\begin{tabular}{|c|c|c|c|}
\hline Reaction & $\bar{\gamma}$ & $\bar{\alpha}$ & $\bar{\beta}$ \\
\hline $\mathrm{HD}^{+}+\mathrm{D}_{2}(\mathrm{o}) \rightarrow \mathrm{D}_{2} \mathrm{H}^{+}(\mathrm{o})+\mathrm{D}$ & $1.05(-09)$ & 0.00 & 0.0 \\
\hline $\mathrm{HD}^{+}+\mathrm{D}_{2}(\mathrm{p}) \rightarrow \mathrm{D}_{2} \mathrm{H}^{+}(\mathrm{p})+\mathrm{D}$ & $1.05(-09)$ & 0.00 & 0.0 \\
\hline $\mathrm{HD}^{+}+\mathrm{D}_{2}(\mathrm{o}) \rightarrow \mathrm{D}_{3}{ }^{+}(\mathrm{m})+\mathrm{H}$ & $5.25(-10)$ & 0.00 & 0.0 \\
\hline $\mathrm{HD}^{+}+\mathrm{D}_{2}(\mathrm{o}) \rightarrow \mathrm{D}_{3}^{+}(\mathrm{o})+\mathrm{H}$ & $5.25(-10)$ & 0.00 & 0.0 \\
\hline $\mathrm{HD}^{+}+\mathrm{D}_{2}(\mathrm{p}) \rightarrow \mathrm{D}_{3}^{+}(\mathrm{m})+\mathrm{H}$ & $1.05(-09)$ & 0.00 & 0.0 \\
\hline $\mathrm{D}_{2} \mathrm{H}^{+}(\mathrm{o})+\mathrm{D} \rightarrow \mathrm{D}_{3}{ }^{+}(\mathrm{m})+\mathrm{H}$ & $0.50(-09)$ & 0.00 & 0.0 \\
\hline $\mathrm{D}_{2} \mathrm{H}^{+}(\mathrm{o})+\mathrm{D} \rightarrow \mathrm{D}_{3}{ }^{+}(\mathrm{o})+\mathrm{H}$ & $0.50(-09)$ & 0.00 & 0.0 \\
\hline $\mathrm{D}_{2} \mathrm{H}^{+}(\mathrm{p})+\mathrm{D} \rightarrow \mathrm{D}_{3}{ }^{+}(\mathrm{m})+\mathrm{H}$ & $1.00(-09)$ & 0.00 & 0.0 \\
\hline $\mathrm{D}_{3}{ }^{+}(\mathrm{m})+\mathrm{H} \rightarrow \mathrm{D}_{2} \mathrm{H}^{+}(\mathrm{p})+\mathrm{D}$ & $1.00(-09)$ & 0.00 & 660.0 \\
\hline $\mathrm{D}_{3}^{+}(\mathrm{o})+\mathrm{H} \rightarrow \mathrm{D}_{2} \mathrm{H}^{+}(\mathrm{o})+\mathrm{D}$ & $1.00(-09)$ & 0.00 & 655.0 \\
\hline $\mathbf{D}_{2} \mathbf{H}^{+}(\mathbf{o})+\mathbf{H D} \rightarrow \mathbf{D}_{3}{ }^{+}(\mathbf{o})+\mathbf{H}_{2}(\mathbf{p})$ & $0.50(-10)$ & 0.00 & 0.0 \\
\hline $\mathbf{D}_{2} \mathbf{H}^{+}(\mathbf{o})+\mathbf{H D} \rightarrow \mathbf{D}_{3}{ }^{+}(\mathbf{m})+\mathbf{H}_{2}(\mathbf{p})$ & $0.50(-10)$ & 0.00 & 0.0 \\
\hline $\mathbf{D}_{2} \mathbf{H}^{+}(\mathbf{p})+\mathbf{H D} \rightarrow \mathbf{D}_{3}{ }^{+}(\mathbf{m})+\mathbf{H}_{2}(\mathbf{p})$ & $1.00(-10)$ & 0.00 & 0.0 \\
\hline $\mathbf{D}_{2} \mathbf{H}^{+}(\mathbf{o})+\mathbf{H D} \rightarrow \mathbf{D}_{3}{ }^{+}(\mathbf{o})+\mathbf{H}_{2}(\mathbf{o})$ & $0.50(-10)$ & 0.00 & 0.0 \\
\hline $\mathbf{D}_{2} \mathbf{H}^{+}(\mathbf{o})+\mathbf{H D} \rightarrow \mathbf{D}_{3}{ }^{+}(\mathbf{m})+\mathbf{H}_{2}(\mathbf{o})$ & $0.50(-10)$ & 0.00 & 0.0 \\
\hline $\mathbf{D}_{2} \mathbf{H}^{+}(\mathbf{p})+\mathbf{H D} \rightarrow \mathrm{D}_{3}{ }^{+}(\mathbf{m})+\mathbf{H}_{2}(\mathbf{o})$ & $1.00(-10)$ & 0.00 & 0.0 \\
\hline $\mathrm{D}_{2} \mathrm{H}^{+}(\mathrm{p})+\mathrm{HD} \rightarrow \mathrm{H}_{2} \mathrm{D}^{+}(\mathrm{p})+\mathrm{D}_{2}(\mathrm{p})$ & $1.00(-10)$ & 0.00 & 144.1 \\
\hline $\mathrm{D}_{2} \mathrm{H}^{+}(\mathrm{o})+\mathrm{HD} \rightarrow \mathrm{H}_{2} \mathrm{D}^{+}(\mathrm{p})+\mathrm{D}_{2}(\mathrm{o})$ & $1.00(-10)$ & 0.00 & 108.4 \\
\hline $\mathrm{D}_{2} \mathrm{H}^{+}(\mathrm{o})+\mathrm{HD} \rightarrow \mathrm{H}_{2} \mathrm{D}^{+}(\mathrm{o})+\mathrm{D}_{2}(\mathrm{o})$ & $1.00(-10)$ & 0.00 & 194.9 \\
\hline $\mathrm{D}_{2} \mathrm{H}^{+}(\mathrm{p})+\mathrm{HD} \rightarrow \mathrm{H}_{2} \mathrm{D}^{+}(\mathrm{o})+\mathrm{D}_{2}(\mathrm{p})$ & $1.00(-10)$ & 0.00 & 230.6 \\
\hline $\mathrm{H}_{2} \mathrm{D}^{+}(\mathrm{p})+\mathrm{D}_{2}(\mathrm{o}) \rightarrow \mathrm{D}_{2} \mathrm{H}^{+}(\mathrm{o})+\mathrm{HD}$ & $8.50(-10)$ & 0.00 & 0.0 \\
\hline $\mathrm{H}_{2} \mathrm{D}^{+}(\mathrm{p})+\mathrm{D}_{2}(\mathrm{p}) \rightarrow \mathrm{D}_{2} \mathrm{H}^{+}(\mathrm{p})+\mathrm{HD}$ & $8.50(-10)$ & 0.00 & 0.0 \\
\hline $\mathrm{H}_{2} \mathrm{D}^{+}(\mathrm{o})+\mathrm{D}_{2}(\mathrm{o}) \rightarrow \mathrm{D}_{2} \mathrm{H}^{+}(\mathrm{o})+\mathrm{HD}$ & $8.50(-10)$ & 0.00 & 0.0 \\
\hline $\mathrm{H}_{2} \mathrm{D}^{+}(\mathrm{o})+\mathrm{D}_{2}(\mathrm{p}) \rightarrow \mathrm{D}_{2} \mathrm{H}^{+}(\mathrm{p})+\mathrm{HD}$ & $8.50(-10)$ & 0.00 & 0.0 \\
\hline $\mathrm{H}_{2} \mathrm{D}^{+}(\mathrm{p})+\mathrm{D}_{2}(\mathrm{p}) \rightarrow \mathrm{D}_{3}^{+}(\mathrm{m})+\mathrm{H}_{2}(\mathrm{p})$ & $8.50(-10)$ & 0.00 & 0.0 \\
\hline $\mathrm{H}_{2} \mathrm{D}^{+}(\mathrm{p})+\mathrm{D}_{2}(\mathrm{o}) \rightarrow \mathrm{D}_{3}^{+}(\mathrm{m})+\mathrm{H}_{2}(\mathrm{p})$ & $4.25(-10)$ & 0.00 & 0.0 \\
\hline $\mathrm{H}_{2} \mathrm{D}^{+}(\mathrm{p})+\mathrm{D}_{2}(\mathrm{o}) \rightarrow \mathrm{D}_{3}{ }^{+}(\mathrm{o})+\mathrm{H}_{2}(\mathrm{p})$ & $4.25(-10)$ & 0.00 & 0.0 \\
\hline $\mathrm{H}_{2} \mathrm{D}^{+}(\mathrm{o})+\mathrm{D}_{2}(\mathrm{o}) \rightarrow \mathrm{D}_{3}^{+}(\mathrm{m})+\mathrm{H}_{2}(\mathrm{o})$ & $4.25(-10)$ & 0.00 & 0.0 \\
\hline $\mathrm{H}_{2} \mathrm{D}^{+}(\mathrm{o})+\mathrm{D}_{2}(\mathrm{o}) \rightarrow \mathrm{D}_{3}^{+}(\mathrm{o})+\mathrm{H}_{2}(\mathrm{o})$ & $4.25(-10)$ & 0.00 & 0.0 \\
\hline $\mathrm{H}_{2} \mathrm{D}^{+}(\mathrm{o})+\mathrm{D}_{2}(\mathrm{p}) \rightarrow \mathrm{D}_{3}^{+}(\mathrm{m})+\mathrm{H}_{2}(\mathrm{o})$ & $8.50(-10)$ & 0.00 & 0.0 \\
\hline $\mathrm{D}_{3}^{+}(\mathrm{m})+\mathrm{H}_{2}(\mathrm{p}) \rightarrow \mathrm{H}_{2} \mathrm{D}^{+}(\mathrm{p})+\mathrm{D}_{2}(\mathrm{p})$ & $1.00(-09)$ & 0.00 & 383.2 \\
\hline $\mathrm{D}_{3}^{+}(\mathrm{m})+\mathrm{H}_{2}(\mathrm{p}) \rightarrow \mathrm{H}_{2} \mathrm{D}^{+}(\mathrm{p})+\mathrm{D}_{2}(\mathrm{o})$ & $0.50(-09)$ & 0.00 & 297.2 \\
\hline $\mathrm{D}_{3}^{+}(\mathrm{o})+\mathrm{H}_{2}(\mathrm{p}) \rightarrow \mathrm{H}_{2} \mathrm{D}^{+}(\mathrm{p})+\mathrm{D}_{2}(\mathrm{o})$ & $1.50(-09)$ & 0.00 & 342.2 \\
\hline $\mathrm{D}_{3}^{+}(\mathrm{m})+\mathrm{H}_{2}(\mathrm{o}) \rightarrow \mathrm{H}_{2} \mathrm{D}^{+}(\mathrm{o})+\mathrm{D}_{2}(\mathrm{p})$ & $1.00(-09)$ & 0.00 & 299.2 \\
\hline $\mathrm{D}_{3}^{+}(\mathrm{m})+\mathrm{H}_{2}(\mathrm{o}) \rightarrow \mathrm{H}_{2} \mathrm{D}^{+}(\mathrm{o})+\mathrm{D}_{2}(\mathrm{o})$ & $0.50(-09)$ & 0.00 & 213.2 \\
\hline $\mathrm{D}_{3}{ }^{+}(\mathrm{o})+\mathrm{H}_{2}(\mathrm{o}) \rightarrow \mathrm{H}_{2} \mathrm{D}^{+}(\mathrm{o})+\mathrm{D}_{2}(\mathrm{o})$ & $1.50(-09)$ & 0.00 & 258.2 \\
\hline $\mathbf{D}_{3}{ }^{+}(\mathbf{m})+\mathbf{H}_{2}(\mathbf{p}) \rightarrow \mathbf{D}_{2} \mathbf{H}^{+}(\mathbf{p})+\mathbf{H D}$ & $1.00(-09)$ & 0.00 & 238.8 \\
\hline $\mathbf{D}_{3}{ }^{+}(\mathbf{m})+\mathrm{H}_{2}(\mathbf{p}) \rightarrow \mathbf{D}_{2} \mathbf{H}^{+}(\mathbf{o})+\mathrm{HD}$ & $0.50(-09)$ & 0.00 & 188.8 \\
\hline $\mathbf{D}_{3}{ }^{+}(\mathbf{o})+\mathrm{H}_{2}(\mathbf{p}) \rightarrow \mathrm{D}_{2} \mathrm{H}^{+}(\mathbf{o})+\mathrm{HD}$ & $1.50(-09)$ & 0.00 & 233.8 \\
\hline $\mathbf{D}_{3}{ }^{+}(\mathbf{m})+\mathbf{H}_{2}(\mathbf{o}) \rightarrow \mathbf{D}_{2} \mathbf{H}^{+}(\mathbf{p})+\mathbf{H D}$ & $1.00(-09)$ & 0.00 & 68.3 \\
\hline $\mathbf{D}_{3}{ }^{+}(\mathbf{m})+\mathbf{H}_{2}(\mathbf{o}) \rightarrow \mathbf{D}_{2} \mathbf{H}^{+}(\mathbf{o})+\mathbf{H D}$ & $0.50(-09)$ & 0.00 & 18.0 \\
\hline $\mathbf{D}_{3}{ }^{+}(\mathbf{o})+\mathbf{H}_{2}(\mathbf{o}) \rightarrow \mathrm{D}_{2} \mathbf{H}^{+}(\mathbf{o})+\mathbf{H D}$ & $1.50(-09)$ & 0.00 & 63.3 \\
\hline $\mathrm{D}_{3}{ }^{+}(\mathrm{m})+\mathrm{e}^{-} \rightarrow \mathrm{D}+\mathrm{D}+\mathrm{D}$ & $2.03(-08)$ & -.52 & 0.0 \\
\hline $\mathrm{D}_{3}^{+}(\mathrm{o})+\mathrm{e}^{-} \rightarrow \mathrm{D}+\mathrm{D}+\mathrm{D}$ & $2.03(-08)$ & -.52 & 0.0 \\
\hline $\mathbf{D}_{3}{ }^{+}(\mathbf{m})+\mathbf{e}^{-} \rightarrow \mathbf{D}_{2}(\mathbf{p})+\mathbf{D}$ & $4.50(-09)$ & -.52 & 0.0 \\
\hline $\mathbf{D}_{3}^{+}(\mathbf{m})+\mathbf{e}^{-} \rightarrow \mathbf{D}_{2}(\mathbf{o})+\mathbf{D}$ & $2.25(-09)$ & -.52 & 0.0 \\
\hline $\mathbf{D}_{3}{ }^{+}(\mathbf{o})+\mathbf{e}^{-} \rightarrow \mathbf{D}_{2}(\mathbf{o})+\mathbf{D}$ & $6.75(-09)$ & -.52 & 0.0 \\
\hline $\mathrm{D}_{2}{ }^{+}(\mathrm{p})+\mathrm{D}_{2}(\mathrm{p}) \rightarrow \mathrm{D}_{3}{ }^{+}(\mathrm{m})+\mathrm{D}$ & $2.10(-09)$ & 0.00 & 0.0 \\
\hline $\mathrm{D}_{2}^{+}(\mathrm{p})+\mathrm{D}_{2}(\mathrm{o}) \rightarrow \mathrm{D}_{3}^{+}(\mathrm{m})+\mathrm{D}$ & $1.05(-09)$ & 0.00 & 0.0 \\
\hline $\mathrm{D}_{2}^{+}(\mathrm{p})+\mathrm{D}_{2}(\mathrm{o}) \rightarrow \mathrm{D}_{3}{ }^{+}(\mathrm{o})+\mathrm{D}$ & $1.05(-09)$ & 0.00 & 0.0 \\
\hline $\mathrm{D}_{2}^{+}(\mathrm{o})+\mathrm{D}_{2}(\mathrm{p}) \rightarrow \mathrm{D}_{3}^{+}(\mathrm{m})+\mathrm{D}$ & $1.05(-09)$ & 0.00 & 0.0 \\
\hline $\mathrm{D}_{2}^{+}(\mathrm{o})+\mathrm{D}_{2}(\mathrm{p}) \rightarrow \mathrm{D}_{3}^{+}(\mathrm{o})+\mathrm{D}$ & $1.05(-09)$ & 0.00 & 0.0 \\
\hline $\mathrm{D}_{2}{ }^{+}(\mathrm{o})+\mathrm{D}_{2}(\mathrm{o}) \rightarrow \mathrm{D}_{3}{ }^{+}(\mathrm{m})+\mathrm{D}$ & $1.05(-09)$ & 0.00 & 0.0 \\
\hline $\mathrm{D}_{2}^{+}(\mathrm{o})+\mathrm{D}_{2}(\mathrm{o}) \rightarrow \mathrm{D}_{3}^{+}(\mathrm{o})+\mathrm{D}$ & $1.05(-09)$ & 0.00 & 0.0 \\
\hline $\mathrm{D}_{3}{ }^{+}(\mathrm{m})+\mathrm{HD} \rightarrow \mathrm{D}_{2} \mathrm{H}^{+}(\mathrm{o})+\mathrm{D}_{2}(\mathrm{p})$ & $0.50(-09)$ & 0.00 & 195.9 \\
\hline $\mathrm{D}_{3}{ }^{+}(\mathrm{m})+\mathrm{HD} \rightarrow \mathrm{D}_{2} \mathrm{H}^{+}(\mathrm{p})+\mathrm{D}_{2}(\mathrm{o})$ & $0.25(-09)$ & 0.00 & 160.1 \\
\hline $\mathrm{D}_{3}{ }^{+}(\mathrm{m})+\mathrm{HD} \rightarrow \mathrm{D}_{2} \mathrm{H}^{+}(\mathrm{p})+\mathrm{D}_{2}(\mathrm{p})$ & $0.50(-09)$ & 0.00 & 246.2 \\
\hline $\mathrm{D}_{3}^{+}(\mathrm{m})+\mathrm{HD} \rightarrow \mathrm{D}_{2} \mathrm{H}^{+}(\mathrm{o})+\mathrm{D}_{2}(\mathrm{o})$ & $0.25(-09)$ & 0.00 & 109.8 \\
\hline
\end{tabular}

Table A.1. continued.

\begin{tabular}{|c|c|c|c|}
\hline Reaction & $\gamma$ & $\alpha$ & $\beta$ \\
\hline $\mathrm{D}_{3}{ }^{+}(\mathrm{o})+\mathrm{HD} \rightarrow \mathrm{D}_{2} \mathrm{H}^{+}(\mathrm{p})+\mathrm{D}_{2}(\mathrm{o})$ & $0.75(-09)$ & 0.00 & 205.4 \\
\hline $\mathrm{D}_{3}{ }^{+}(\mathrm{o})+\mathrm{HD} \rightarrow \mathrm{D}_{2} \mathrm{H}^{+}(\mathrm{o})+\mathrm{D}_{2}(\mathrm{o})$ & $3.75(-10)$ & 0.00 & 155.0 \\
\hline $\mathrm{D}_{3}{ }^{+}(\mathrm{o})+\mathrm{HD} \rightarrow \mathrm{D}_{2} \mathrm{H}^{+}(\mathrm{o})+\mathrm{D}_{2}(\mathrm{p})$ & $3.75(-10)$ & 0.00 & 241.0 \\
\hline $\mathrm{D}^{+}+\mathrm{D}_{2}(\mathrm{o}) \rightarrow \mathrm{D}^{+}+\mathrm{D}_{2}(\mathrm{p})$ & $1.98(-09)$ & 0.00 & 86.0 \\
\hline $\mathrm{D}^{+}+\mathrm{D}_{2}(\mathrm{p}) \rightarrow \mathrm{D}^{+}+\mathrm{D}_{2}(\mathrm{o})$ & $1.32(-09)$ & 0.00 & 0.0 \\
\hline $\mathrm{D}_{2} \mathrm{H}^{+}(\mathrm{p})+\mathrm{D}_{2}(\mathrm{o}) \rightarrow \mathrm{D}_{2} \mathrm{H}^{+}(\mathrm{o})+\mathrm{D}_{2}(\mathrm{p})$ & $1.98(-09)$ & 0.00 & 36.0 \\
\hline $\mathrm{D}_{2} \mathrm{H}^{+}(\mathrm{o})+\mathrm{D}_{2}(\mathrm{p}) \rightarrow \mathrm{D}_{2} \mathrm{H}^{+}(\mathrm{p})+\mathrm{D}_{2}(\mathrm{o})$ & $1.98(-09)$ & 0.00 & 0.0 \\
\hline $\mathrm{D}_{2} \mathrm{H}^{+}(\mathrm{o})+\mathrm{D}_{2}(\mathrm{o}) \rightarrow \mathrm{D}_{2} \mathrm{H}^{+}(\mathrm{p})+\mathrm{D}_{2}(\mathrm{p})$ & $1.98(-09)$ & 0.00 & 136.0 \\
\hline $\mathrm{D}_{2} \mathrm{H}^{+}(\mathrm{p})+\mathrm{D}_{2}(\mathrm{p}) \rightarrow \mathrm{D}_{2} \mathrm{H}^{+}(\mathrm{o})+\mathrm{D}_{2}(\mathrm{o})$ & $8.80(-10)$ & 0.00 & 0.0 \\
\hline $\mathbf{D}_{3}{ }^{+}(\mathbf{o})+\mathbf{D}_{2}(\mathbf{o}) \rightarrow \mathbf{D}_{3}{ }^{+}(\mathbf{m})+\mathbf{D}_{2}(\mathbf{p})$ & $1.98(-09)$ & 0.00 & 131.0 \\
\hline $\mathbf{D}_{3}{ }^{+}(\mathbf{m})+\mathbf{D}_{2}(\mathbf{p}) \rightarrow \mathbf{D}_{3}{ }^{+}(\mathbf{o})+\mathbf{D}_{2}(\mathbf{o})$ & $5.50(-10)$ & 0.00 & 0.0 \\
\hline $\mathbf{D}_{3}{ }^{+}(\mathbf{m})+\mathbf{D}_{2}(\mathbf{o}) \rightarrow \mathbf{D}_{3}{ }^{+}(\mathbf{o})+\mathbf{D}_{2}(\mathbf{p})$ & $1.98(-09)$ & 0.00 & 41.0 \\
\hline $\mathbf{D}_{3}{ }^{+}(\mathbf{o})+\mathbf{D}_{2}(\mathbf{p}) \rightarrow \mathbf{D}_{3}{ }^{+}(\mathbf{m})+\mathbf{D}_{2}(\mathbf{o})$ & $3.17(-09)$ & 0.00 & 0.0 \\
\hline $\mathbf{D}_{3}{ }^{+}(\mathbf{o})+\mathbf{H D} \rightarrow \mathrm{D}_{3}^{+}(\mathbf{m})+\mathbf{H D}$ & $0.66(-09)$ & 0.00 & 46.5 \\
\hline $\mathrm{D}_{3}{ }^{+}(\mathrm{m})+\mathrm{HD} \rightarrow \mathrm{D}_{3}{ }^{+}(\mathrm{o})+\mathrm{HD}$ & $0.28(-09)$ & 0.00 & 0.0 \\
\hline $\mathrm{g}^{-}+\mathrm{D}_{2} \mathrm{H}^{+}(\mathrm{p}) \rightarrow \mathrm{g}^{0}+\mathrm{HD}+\mathrm{D}$ & $2.38(-07)$ & 0.50 & 0.0 \\
\hline $\mathrm{g}^{-}+\mathrm{D}_{2} \mathrm{H}^{+}(\mathrm{p}) \rightarrow \mathrm{g}^{0}+\mathrm{D}_{2}(\mathrm{p})+\mathrm{H}$ & $1.19(-07)$ & 0.50 & 0.0 \\
\hline $\mathrm{g}^{-}+\mathrm{D}_{2} \mathrm{H}^{+}(\mathrm{p}) \rightarrow \mathrm{g}^{0}+\mathrm{D}+\mathrm{D}+\mathrm{H}$ & $3.57(-07)$ & 0.50 & 0.0 \\
\hline $\mathrm{g}^{-}+\mathrm{D}_{2} \mathrm{H}^{+}(\mathrm{o}) \rightarrow \mathrm{g}^{0}+\mathrm{HD}+\mathrm{D}$ & $2.38(-07)$ & 0.50 & 0.0 \\
\hline $\mathrm{g}^{-}+\mathrm{D}_{2} \mathrm{H}^{+}(\mathrm{o}) \rightarrow \mathrm{g}^{0}+\mathrm{D}_{2}(\mathrm{o})+\mathrm{H}$ & $1.19(-07)$ & 0.50 & 0.0 \\
\hline $\mathrm{g}^{-}+\mathrm{D}_{2} \mathrm{H}^{+}(\mathrm{o}) \rightarrow \mathrm{g}^{0}+\mathrm{D}+\mathrm{D}+\mathrm{H}$ & $3.57(-07)$ & 0.50 & 0.0 \\
\hline $\mathrm{g}^{0}+\mathrm{D}_{2} \mathrm{H}^{+}(\mathrm{p}) \rightarrow \mathrm{g}^{+}+\mathrm{HD}+\mathrm{D}$ & $2.38(-07)$ & 0.50 & 0.0 \\
\hline $\mathrm{g}^{0}+\mathrm{D}_{2} \mathrm{H}^{+}(\mathrm{p}) \rightarrow \mathrm{g}^{+}+\mathrm{D}_{2}(\mathrm{p})+\mathrm{H}$ & $1.19(-07)$ & 0.50 & 0.0 \\
\hline $\mathrm{g}^{0}+\mathrm{D}_{2} \mathrm{H}^{+}(\mathrm{p}) \rightarrow \mathrm{g}^{+}+\mathrm{D}+\mathrm{D}+\mathrm{H}$ & $3.57(-07)$ & 0.50 & 0.0 \\
\hline $\mathrm{g}^{0}+\mathrm{D}_{2} \mathrm{H}^{+}(\mathrm{o}) \rightarrow \mathrm{g}^{+}+\mathrm{HD}+\mathrm{D}$ & $2.38(-07)$ & 0.50 & 0.0 \\
\hline $\mathrm{g}^{0}+\mathrm{D}_{2} \mathrm{H}^{+}(\mathrm{o}) \rightarrow \mathrm{g}^{+}+\mathrm{D}_{2}(\mathrm{o})+\mathrm{H}$ & $1.19(-07)$ & 0.50 & 0.0 \\
\hline $\mathrm{g}^{0}+\mathrm{D}_{2} \mathrm{H}^{+}(\mathrm{o}) \rightarrow \mathrm{g}^{+}+\mathrm{D}+\mathrm{D}+\mathrm{H}$ & $3.57(-07)$ & 0.50 & 0.0 \\
\hline $\mathbf{g}^{-}+\mathbf{D}_{3}^{+}(\mathbf{m}) \rightarrow \mathbf{g}^{0}+\mathbf{D}_{2}(\mathbf{p})+\mathbf{D}$ & $2.17(-07)$ & 0.50 & 0.0 \\
\hline $\mathbf{g}^{-}+\mathbf{D}_{3}^{+}(\mathbf{m}) \rightarrow \mathbf{g}^{0}+\mathbf{D}_{2}(\mathbf{o})+\mathbf{D}$ & $1.09(-07)$ & 0.50 & 0.0 \\
\hline $\mathrm{g}^{-}+\mathrm{D}_{3}{ }^{+}(\mathrm{m}) \rightarrow \mathrm{g}^{0}+\mathrm{D}+\mathrm{D}+\mathrm{D}$ & $3.26(-07)$ & 0.50 & 0.0 \\
\hline $\mathbf{g}^{-}+\mathbf{D}_{3}{ }^{+}(\mathbf{o}) \rightarrow \mathbf{g}^{0}+\mathbf{D}_{2}(\mathbf{o})+\mathbf{D}$ & $3.26(-07)$ & 0.50 & 0.0 \\
\hline $\mathrm{g}^{-}+\mathrm{D}_{3}{ }^{+}(\mathrm{o}) \rightarrow \mathrm{g}^{0}+\mathrm{D}+\mathrm{D}+\mathrm{D}$ & $3.26(-07)$ & 0.50 & 0.0 \\
\hline $\mathrm{g}^{0}+\mathrm{D}_{3}{ }^{+}(\mathrm{m}) \rightarrow \mathrm{g}^{+}+\mathrm{D}_{2}(\mathrm{p})+\mathrm{D}$ & $2.17(-07)$ & 0.50 & 0.0 \\
\hline $\mathrm{g}^{0}+\mathrm{D}_{3}{ }^{+}(\mathrm{m}) \rightarrow \mathrm{g}^{+}+\mathrm{D}_{2}(\mathrm{o})+\mathrm{D}$ & $1.09(-07)$ & 0.50 & 0.0 \\
\hline $\mathrm{g}^{0}+\mathrm{D}_{3}{ }^{+}(\mathrm{m}) \rightarrow \mathrm{g}^{+}+\mathrm{D}+\mathrm{D}+\mathrm{D}$ & $3.26(-07)$ & 0.50 & 0.0 \\
\hline $\mathrm{g}^{0}+\mathrm{D}_{3}^{+}(\mathrm{o}) \rightarrow \mathrm{g}^{+}+\mathrm{D}_{2}(\mathrm{o})+\mathrm{D}$ & $3.26(-07)$ & 0.50 & 0.0 \\
\hline $\mathrm{g}^{0}+\mathrm{D}_{3}^{+}(\mathrm{o}) \rightarrow \mathrm{g}^{+}+\mathrm{D}+\mathrm{D}+\mathrm{D}$ & $3.26(-07)$ & 0.50 & 0.0 \\
\hline
\end{tabular}

